\title{
Fox01, a Potential Therapeutic Target, Regulates Mitochondrial Dysfunction and Pyroptosis in LPS- Induced Human Cervical Cancer Cells
}

Huizhi Wang

Hongqi Hospital

Zhi Ma

Hongqi hospital

Fanshu Gao

Hongqi hospital

Wei Jiang

Hongqi hospital

Yang Li

Hongqi hospital

Shuping Li ( $\nabla$ gaolingjuan@njmu.edu.cn )

Hongqi hospital

\section{Research Article}

Keywords: LPS, Fox01, Mitochondrial function, pyroptosis

Posted Date: November 24th, 2020

DOI: https://doi.org/10.21203/rs.3.rs-110897/v1

License: (1) This work is licensed under a Creative Commons Attribution 4.0 International License.

Read Full License 


\section{Abstract}

Background: Chronic inflammation plays an important role in the development of cervical cancer. Studies have demonstrated that transcription factors forkhead box protein 01 (Fox01) have been reported to play important roles in various cancers.

Aim: The purpose of this study was to investigate the effect of Fox01 gene on lipopolysaccharide (LPS)induced inflammation and intracellular pyroptosis in the development and progression of human cervical cancer cells ( $\mathrm{SiHa})$.

Methods: In this study, Fox01 expression was examined using real-time polymerase chain reaction (PCR), western blotting and immunohistochemical staining. SiHa cells migration and proliferation was detected using the transwell assay and ${ }^{3} \mathrm{H}-\mathrm{TdR}$ assay. Mitochondrial function was assessed based on reactive oxygen species (ROS) generation and changes in the mitochondrial membrane potential $(\Delta \Psi \mathrm{m})$.

Results: Our study demonstrated that LPS inhibited FoxO1 gene expression, and the silence of Fox01 gene caused the accumulation of ROS, decreases in the $\triangle \Psi \mathrm{m}$ and mitochondrial morphology change). However, either overexpression of FoxO1 or metformin could reverse the LPS-induced mitochondrial dysfunction, cell pyroptosis, migration and proliferation.

Conclusions: Our study indicated that FoxO1 as a potential therapeutic target to cure against LPSinduced human cervical cancer in a mitochondria-dependent manner.

\section{Background}

Cervical cancer is the second most common gynaecological malignant and is responsible for substantial number of morbidities and mortalities worldwide [1]. In China, there were $>150,000$ diagnosed newcases and $>20,000$ deaths cases annually [2]. Molecular and epidemiological studies have suggested that the normal cervical epithelium cells transforms into preneoplastic cervical intraepithelial neoplasia (CIN), which eventually develops into invasive cervical cancer cells, the development of cervical cancer is multistep process that involving multiple genes $[3,4]$. Therefore, it is very important to clarify molecular mechanisms to find the preventive strategies, early clinical diagnostic methods, and effective therapies to treat cervical tumors.

The relationship between chronic inflammation and cancer has always been concerned. Chronic inflammation is the major cause of malignancies, such as prostate cancer [5], cervical cancer [6] and ovarian cancer [7] and so on. Some studies has addressed that infection can trigger a range of inflammatory response, and inflammation can promote the cancer progression [8]. The effects of inflammation on tumorigenesis include the regulation of the tumor microenvironment through producing inflammatory cytokines, reactive oxygen species and transcriptional factors [9]. Lipopolysaccharide (LPS) is a gram-negative bacterial antigen that participates in and promotes the progression and metastasis of a variety of tumors [10]. It is well known that LPS could promote the proliferation and invasion of cervical 
cancer cells by stimulating the secretion of interleukin-1 beta (IL-1ß), induction of downstream cytokines and pyroptosis, enhancing the inflammatory microenvironment. IL-1 $\beta$, a generally accepted product of pyroptotic cell death and key cytokine in cancer development and progression, has already been chosen as a target for cancer immunotherapy [11]. However, LPS promote the underlying mechanisms of progression of cervical carcinoma is not entirely clear.

FoxO1 is a member of the forkhead box 0 (FoxO) family, which is recognized as negative regulator of the $\mathrm{PI} 3-\mathrm{k} /$ Akt signaling pathway, and is considered as tumor suppressors [12]. Several tissue culture studies demonstrate that FoxO1 is down-regulated in a wide variety of cancers, such as breast and uterine cervix cancers [13]. Activation of Fox01 results in regulating cell-cycle arrest, pyroptosis, DNA damage repair, and detoxification of reactive oxygen species [14]. Therefore, this study was to explore whether Fox01 involved in pyroptosis regulation and mitochondrial dysfunction in SiHa cells. Finally, we confirmed the possibility that FoxO1 served as the therapeutic target to cure human cervical cancer.

\section{Materials And Methods}

\section{Chemicals and reagents}

The cervical epithelial SiHa cells line were obtained from the American Type Culture Collection (ATCC, Manassas, VA). Dulbecco's Modified Eagle's Medium (DMEM) powder, fetal bovine serum (FBS) and Lglutamine were obtained from the Gibco (Grand Island, NY, USA); The Lipofectamine ${ }^{\circledR} 2000$ transfection reagent was purchased from Santa Cruz (Santa Cruz, California, USA). Dimethyl sulfoxide (DMSO) and Lipopolysaccharide (LPS) was obtained from Sigma-Aldrich (St. Louis, MO, USA). Fox01 small-interfering RNA (siRNA) were designed and synthesized by Wuhan Genesil Biotechnology Co. Ltd (Wuhan, China). Fox01 and actin gene primers were designed and synthesized by Shanghai Boya Biotechnology Co. Ltd (Shanghai, China).

\section{Cell culture}

SiHa cells were grown in DMEM medium containing with $1 \%$ nonessential amino acids, $2 \mathrm{mM}$ of glutamine, 100 units $/ \mathrm{mL}$ penicillin, $100 \mu \mathrm{g} / \mathrm{mL}$ streptomycin and $10 \%$ FBS. SiHa cells were cultured in a 5 $\% \mathrm{CO}_{2}$ incubator at $37^{\circ} \mathrm{C}$ to $80-90 \%$ confluence, and then treated with $40 \mu \mathrm{g} / \mathrm{ml} \mathrm{LPS}$ for $24 \mathrm{~h}$ or other reagents at the indicated times and concentrations. The choice of LPS concentrations was based on previous reports [21].

\section{Cloning and transfection of Fox01 vector plasmids}

The pcDNA 3.1 expression plasmid (Invitrogen, Carlsbad, CA) expressing pcDNA3.1-Fox01 vector was created at Hangzhou Hibio Bio-tech Co., Ltd. (Hangzhou, Zhejiang, China). The pcDNA3.1 empty vector was chosen as a negative control. Fox01: Primer-F: 5'-GCG GGC TGG AAG AAT TCA AT -3' and Primer-R: 5'- TCC AGT TCC TTC ATT CTG CA-3'. The PCR product was digested with BamHI and EcoRI and ligated into pcDNA 3.1 expression plasmid. The resulting pcDNA3.1-Fox01 vector or pcDNA3.1 empty vector was 
then transfected into SiHa cells using Lipofectamine 2000 according to the manufacturer's instructions. Briefly, before transfection, the SiHa cells were serum starved for $24 \mathrm{~h}, 500$ pmol of pcDNA3.1-Fox01 vector and $10 \mu \mathrm{L}$ of Lipofectamine 2000 were diluted in $750 \mu \mathrm{L}$ of OptiMEM (Life Technologies, Gaithersburg, MD, USA). The solution was pre-incubated for $45 \mathrm{~min}$ at $37^{\circ} \mathrm{C}$, then overlaid onto the $\mathrm{SiHa}$ cells for $2 \mathrm{~h}$, finally, $2 \mathrm{ml}$ of growth medium ( $20 \%$ foetal bovine serum) were added for further cultured.

\section{Fox01 siRNA-expressing plasmid construction}

The Fox01 siRNA expression plasmid was constructed using the primers 5'-CCC AAG GCT TTG GTC CTA TC-3' (forward), 5'-GCC GGA TTC ACT GTA TTC TTG-3' (reverse). Negative siRNAs were sequenced (An unrelated gene) as follows: 5'- GUA CCG CAC GUC AUU CGU AUC-3' (forward), 5'-UAC GAA UGA CGU GCG GUA CGU-3' (reverse). The reconstituted FoxO1 siRNA expression plasmid transfected into SiHa cells, along with LPS $(40 \mu \mathrm{g} / \mathrm{ml})$. The SiHa cell mitochondrial function and biological function was measured.

\section{Real-time quantitative polymerase chain reaction (real-time qPCR)}

Extraction of total RNA from SiHa cells was performed using RNAiso Plus (TakaRa, China). Then, $10 \mu \mathrm{L}$ of total RNA was reverse-transcribed into complementary DNA (cDNA) using the PrimeScript cDNA Synthesis Kit (Takara, Japan). The following sequences were used to detect Fox01 mRNA level: Primer-F: 5'-GCG GGC TGG AAG AAT TCA AT -3' and Primer-R: 5'-TCC AGT TCC TTC ATT CTG CA-3'. $\beta$-actin sense: 5'-CGA GCG GGA AAT CGT GCG TGA CAT -3'; and antisense, 5'-CGT CAT ACT CCT GCT TGC TGA TCC ACA TCT -3'. Real-time qPCR reactions were performed using the ABI PRISM 7500 Sequence Detection

System (Applied Biosystems). The relative level of FoxO1 mRNA was calculated using the threshold cycle $\left(2^{-\triangle \Delta C T}\right)$ method [22].

\section{Western blot analysis}

The SiHa cells were thawed in lysis buffer containing containing $0.5 \%$ Deoxycholate, $50 \mathrm{mM}$ Tris- $\mathrm{HCl}(\mathrm{pH}$ 7.0 ), $0.1 \%$ Triton $X-100,150 \mathrm{mM} \mathrm{NaCl}, 0.1 \%$ sodium dodecyl sulfate (SDS), and $1 \mathrm{mM}$ ethylenediaminetetraacetic acid (EDTA). Total proteins were electrophoresed using a $10-15 \%$ gradient SDS-polyacrylamide gel and subsequently transferred onto a polyvinylidene fluoride (PVDF) membrane. The membranes were then blocked in $5 \%$ non-fat milk in PBST for $1 \mathrm{~h}$, and then incubated with primary antibodies specific to Fox01 (1: 1000 dilution, Abcam: ab52587), Caspase-1 (1: 500 dilution, Santa Cruz, CA, USA) and actin (1: 2000; ab8227, Abcam). The membrane were washed and then incubated for $1 \mathrm{~h}$ at room temperature with horseradish peroxidase (HRP)-conjugated secondary antibody (1: 4000).

Visualization of protein band was quantified using the Enhanced Chemiluminescence Western Detection System (Cell Signaling Technology, Beverly, MA, USA).

\section{Immunohistochemistry}

The SiHa cells were digested by trypsin and pelleted at $1000 \mathrm{X}$ for $30 \mathrm{~min}$ at $4{ }^{\circ} \mathrm{C}$. The mass were cut into $5 \mu \mathrm{m}$ slice, then treated with $4 \% \mathrm{H}_{2} \mathrm{O}_{2}$ for $30 \mathrm{~min}$. The antigen retrieval was underwent in $0.01 \mathrm{M}$ citrate 
buffer (pH 6.0) for $25 \mathrm{~min}$. The slides were incubated with Fox01 antibodies (dilution, 1: 100, Santa Cruz Biotechnology) for $30 \mathrm{~min}$ at $37^{\circ} \mathrm{C}$ and 3, 3'-diaminobenzidine Sigma-D8001 staining kit (Sigma Aldrich; Merck KGaA) staining. Positive (brown) staining indicates the presence of the HAX-1 protein, as detected by light microscopy (magnification, $\mathrm{x} 200$ ).

\section{ELISA analysis}

The production of IL-1 $\beta$ was detected by ELISA kit (R\&D System, Minneapolis, MN). $200 \mu \mathrm{L}$ of supernatant was added to each well and incubated for $45 \mathrm{~min}$ at $37^{\circ} \mathrm{C}$. After incubation, the plate was washed four times, and was then added with $200 \mu \mathrm{l}$ of conjugate for $45 \mathrm{~min}$ at $37^{\circ} \mathrm{C}$. After washing four times, $200 \mu \mathrm{L}$ substrate solution was added for $20 \mathrm{~min}$ in the dark. The absorbance was read using an ELISA Reader at $450 \mathrm{~nm}$ after the addition of $2 \mathrm{M}$ sulfuric acid. The level of IL-1 $\beta$ in culture media was calculated according to a standard curve.

\section{Electron microscope}

The cultured SiHa cells were digested by trypsin and pelleted at $12000 \times \mathrm{g}$ for $10 \mathrm{~min}$ at $4{ }^{\circ} \mathrm{C}$. The cells mass were fixed with $2 \%$ paraformaldehyde and placed in $2.5 \%$ glutaraldehyde in $0.1 \mathrm{M}$ cacodylate buffer $(\mathrm{pH}$ 7.4). Then the pellet was washed twice and dehydrated in a gradient series of ethanol solutions $(25 \%, 50 \%, 70 \%, 80 \%, 90 \%$ and twice $100 \%$ for $15 \mathrm{~min})$. The sample was treated with acetone and flat-embedded in Durcupan (Fluka Chemic AG, Buchs, Switzerland), and then sectioned to 60-70 nm thickness on 300 mesh copper slot grids. The ultrastructure of cells was examined at $5200 \mathrm{X}$ magnification (Observation of mitochondrial morphology) and $2500 \mathrm{X}$ magnification (Observation of cell apoptosis morphology), and the images were viewed under a Zeiss $10^{9}$ electron microscope (Carl Zeiss, Oberkochen, Germany).

\section{Assay of intracellular ROS}

The production of intracellular ROS was measured by a $\mathrm{H}_{2}$ DCFDA based ROS assay kit (Beyotime, Shanghai, China). Briefly, the SiHa cells were applied with different treatments, cells were harvested, and then incubated with $10 \mu \mathrm{M}$ final concentration of $\mathrm{H}_{2}$ DCFDA for 30 min in the dark at $37^{\circ} \mathrm{C}$. Flow cytometry (BD FACSCalibur, San Jose, CA, USA) was used to detect the intracellular ROS generation with excitation wavelength and the emission wavelength at $488 \mathrm{~nm}$ and $530 \mathrm{~nm}$ respectively.

\section{Measurement of mitochondrial membrane potential $(\Delta \Psi \mathrm{m})$}

Loss of mitochondrial membrane potential $(\Delta \Psi \mathrm{m})$ was examined in SiHa cells using the fluorescent cationic dye JC-1 (Molecular Probes; Thermo Fisher Scientific, Inc.). The SiHa cells were applied with different treatments and then stained with $10 \mu \mathrm{M} \mathrm{JC}-1$ for 20 min at RT. The fluorescence intensities with the excitation wavelength and the emission wavelength at $485 \mathrm{~nm}$ and $530 \mathrm{~nm}$ respectively using fluorescence microscopy (magnification, x200).

\section{SiHa cells migration analysis}


The siHa cells migration were detected using the transwell (Corning Incorporated, Corning, NY, USA) assay. The SiHa cells were starved for $24 \mathrm{~h}$ and were then harvested. SiHa cells were resuspended in culture medium at least $2 \times 10^{6}$ cells $/ \mathrm{ml}$. The upper chamber was filled with $100 \mu \mathrm{l}$ cell suspension and the lower chamber was added with $600 \mu \mathrm{l}$ culture medium containing $20 \% \mathrm{FBS}$. The chambers were incubated for $24 \mathrm{~h}$ at $37^{\circ} \mathrm{C}$. The migration ability of SiHa cells were fixes with $95 \%$ ethanol and then stained with $0.1 \%$ crystal violet staining. In five different fields per filter, the migrated cells were counted under a microscopic $(\times 400)$.

\section{SiHa cell proliferation assay}

The SiHa cells were starved for $24 \mathrm{~h}$ and were then harvested. SiHa cells were resuspended in culture medium at least $2 \times 10^{6}$ cells $/ \mathrm{ml}$. ${ }^{3} \mathrm{H}$-thymidine were incorporated into SiHa cells to indicate DNA synthesis. The cultured SiHa cells were trypsinized and were then harvested onto a glass fiber filter paper. Scintillation solution was added to detect the radioactivity, which was counted by a TopCount NxT scintillation counter (LKB Instruments, Mount Waverly, Victoria, Australia).

\section{Statistical analysis}

All data are presented as mean \pm standard deviation (SD). Student's $t$ test was used to compare the means of two groups. $p$-values less than 0.05 were considered significant $\left({ }^{\star} p<0.05 ;{ }^{\star \star} p<0.01 ;{ }^{*} p>\right.$ 0.05). Statistical significance was calculated using SPSS18.0. All experiments were performed at least three independent experiments.

\section{Results}

\section{The effects of LPS on the FoxO1 expression in SiHa cells}

Firstly, the effect of LPS on the expression of FoxO1 in SiHa cells was evaluated. qRT-PCR showed that LPS stimulation apparently inhibited the mRNA level of Fox01 gene (Fig. 1a). Western blot results showed that the expression of Fox01 protein in LPS group were obviously decreased when compared with the DMSO group (Fig. 1b). In addition, immunohistochemical staining indicated that FoxO1 expression was significantly decreased in the cytoplasm of SiHa cells in LPS group (Fig. 1c).

\section{Silencing of FoxO1 induced mitochondrial dysfunction in SiHa cell}

The effect of the Fox01 gene on the production of ROS and changes in the mitochondrial membrane potential in SiHa cells was explored in this study. Data indicated that ROS accumulation in the FoxO1 siRNA vector group were enhanced by approximately 2.85 -fold compared with mock treatment (Fig. 2a). In addition, the silence of the Fox01 decreased mitochondrial membrane potential approximately $63.4 \%$ compared to those in mock group $(p<0.01)$. However, the negative siRNA group, the mitochondrial membrane potential showed no obvious changes when compared with mock group (Fig. 2b). 
Transmission electron microscopy images indicated the the silence of the FoxO1 gene induced mitochondrial morphology change containing mitochondrial swelling and vesicular formation (Fig. 2c).

\section{Effect of FoxO1 overexpression on mitochondrial function in LPS-stimulated SiHa cells}

Pretransfection with Fox01 vector prevented LPS-induced ROS production, the ROS levels in the LPS (+), Fox01 vector $(+)$ group were decreased compared with those in the LPS alone-treated group $(p<0.01)$. When compared with LPS (+), Fox01 vector $(+)$ treatment, treatment with LPS $(+)$ and empty vector $(+)$ caused a significant increase in ROS accumulation. In addition, treatment with metformin may reverse LPS-induced ROS production ( $p<0.01$, Fig. 3a, metformin can protect mitochondrial function and promote mitochondrial metabolism). Mitochondrial dysfunction was manifested as decreases in the mitochondrial membrane potential. We observed that overexpression of Fox01 or protect mitochondrial function maintained the mitochondrial membrane potential at normal levels in cells exposed to LPS. The mitochondrial membrane potential in the LPS $(+)$ and empty vector $(+)$ group were significantly decreased compared to those in the LPS $(+)$ and Fox01 vector $(+)$ group $(p<0.01)$. In addition, the mitochondrial membrane potential in the LPS $(+)$ and metformin $(+)$ group were significantly increased compared to those in the LPS $(+)$ and empty vector $(+)$ group $(p<0.01$, Fig. 3b). As shown in Fig. $3 c$, transmission electron microscopy images indicated the mitochondrial morphology change including mitochondrial swelling and vesicular formation in LPS alone-treated group or LPS (+) and empty vector (+) group. However, enhanced FoxO1 gene or protect mitochondrial function could maintain the integrity of mitochondrial morphology.

\section{Effect of FoxO1 overexpression on biological function in LPS-stimulated SiHa cells}

In this study, ELISA analysis showed that LPS stimulation significantly increased the extracellular levels of IL-1 $\beta$ in culture media. Pretransfection with Fox01 vector or metformin attenuated LPS-induced the IL$1 \beta$ generation, the levels of IL-1 $\beta$ in the LPS $(+)$, Fox01 vector ( + ) group were reduced compared with those in the LPS alone-treated group $(p<0.001)$. When compared with LPS $(+)$, Fox01 vector $(+)$ treatment, treatment with LPS $(+)$ and empty $(+)$ caused a significant increase in IL-1 $\beta$ levels $(p<0.01)$. Treatment with metformin may reduce LPS-induced IL-1 $\beta$ production $(p<0.01$, Fig. $4 \mathrm{a})$ ). Activation of caspase- 1 is required during IL-1 $\beta$ production, as shown in Fig. $4 \mathrm{~b}$, LPS increased the cleavage of caspase-1, while treatment with Fox01 vector or metformin decreased LPS-induced the expression of caspase-1, however, compared with LPS $(+)$ and Fox01 vector $(+)$ treatment, treatment with LPS $(+)$ and empty $(+)$ caused a significant increase in caspase-1 levels $(p<0.01)$. For further evaluation the role of FoxO1 in LPS-induced SiHa cell migration and proliferation ability, transwell experiments and ${ }^{3} \mathrm{HTdR}$ incorporation assay showed that the migration and proliferation cells in the LPS (+), FoxO1 vector (+)treated group or LPS $(+)$, metformin $(+)$ group reduced compared with the LPS alone group $(p<0.01)$. However, compared with LPS (+), Fox01 vector $(+)$ treatment, treatment with LPS (+) and empty vector (+) caused a significantly enhanced in the migration and proliferation cells $(p<0.01$, Fig. 4c-d).

\section{Discussion}


LPS is a common inflammatory inducer, and its exposure activates many components of chronic inflammation, such as the production and release of cytokines [15]. LPS exposure is closely related to the survival, proliferation, invasion and metastasis of tumor cells by stimulating the production of TNF-a and $\mathrm{IL}-6$, and the serum levels of these cytokines are associated with prostate cancer stage [16]. The immunological stress model provided by LPS is used to release of excessive inflammatory mediators, such as IL-1 $\beta$, which can also cause the occurrence of cervical cancer [17]. Previous studies have indicated that LPS stimulation could activate the TLR4-NF-KB signalling pathway in SiHa cells, which activates the inflammatory mediators such as IL-1 $\beta$ [18]. The present study firstly showed that LPS stimulation inhibited the mRNA and protein expression of FoxO1 in $\mathrm{SiHa}$ cells, and consequently promoting the release of IL-1 $\beta$, which illustrated that Fox01 gene might also play a role in the promoting the progression of cervical cancer.

Transcription factor Fox01 participates in many important functions such as the regulating cell cycle progression, apoptosis, tumor suppression, cell differentiation and metabolism, and oxidative stress resistance [19-21]. Previous studies have shown that Fox01 is significantly upregulated in epithelial ovarian cancer, whereas FoxO1 is significantly down-regulated in tumors of other organs, such as cervix, prostate, breast, and endometrium [22-24]. The function of FoxO1 in the carcinogenesis is also controversial, it was reported that siRNA-mediated Fox01 silence in OVCA429 and OVCA433 cells resulted in decreased cell proliferation. In addition, migration experiment showed that FoxO1 knockdown had a significant negative effect on the epithelial ovarian cancer cells migration [25]. However recent studies have shown that Fox01 plays an anti-tumor role by regulating pro-apoptotic genes such as BIM, FasL and TRAIL, which in turn inhibits the growth of various tumors such as glioblastoma and cervical cancer [2627]. In our study, we examined the role of Fox01 in human cervical cancer cells growth (proliferation) and metastasis (migration) in functional studies. Our results indicated that overexpression of FoxO1 gene attenuated LPS-induced migration and proliferation of SiHa cell.

The form of FoxO1 is associated with protection of mitochondrial function [28]. Studies have shown that mitochondrial dysfunction is associated with loss of cell function, apoptosis and pyroptosis induced by oxidative stress, characterized by excessive ROS production in defective mitochondria [29]. Mitochondrial dysfunction is a kind of dysfunction in biochemical process, which is characterized by the accumulation of ROS can lead to the loss of ATP, which disrupts the integrity of mitochondrial membrane, leading to mitochondrial dysfunction and pyroptosis [30]. Previous studies have shown that cobalt protoporphyrin upregulates FoxO1 expression, further increases the expression of HO-1 gene and other oxidative stressresponsive genes and reduces the production of mitochondria-derived ROS, which are partially mediated by FoxO1 [31]. Our study indicates that FoxO1 gene silencing increases ROS production and loss of the $\Delta \Psi \mathrm{m}$, and changes the mitochondrial morphology. However, either overexpression of FoxO1 or metformin could reverse the LPS-induced mitochondrial dysfunction, cell pyroptosis, migration and proliferation. These data indicated the role of FoxO1-mediated mitochondrial function in LPS-induced pyroptosis of SiHa cells. 


\section{Conclusion}

The current study indicates that LPS induces the release of IL-1 $\beta$ and other inflammatory cytokines modulated partially by Fox 01 , and that Fox 01 plays an important role in protecting mitochondrial function, including reducing of ROS generation and maintaining the mitochondrial membrane integrity. Either overexpression of FoxO1 or metformin could reverse the LPS-induced mitochondrial dysfunction, cell pyroptosis, migration and proliferation. Taken together, our study identified FoxO1 as a potential therapeutic target for human cervical cancer in a mitochondrial-dependent manner.

\section{Abbreviations}

CIN: Cervical intraepithelial neoplasia; Fox01: Forkhead box protein 01; LPS: Lipopolysaccharide; Realtime PCR: Real-time polymerase chain reaction; ROS: Reactive oxygen species; IL-1 $\beta$ : Interleukin-1 beta; ATCC: American Type Culture Collection; DMEM: Dulbecco's Modified Eagle's Medium; FBS: Fetal bovine serum; DMSO: Dimethyl sulfoxide; siRNA: small-interfering RNA; SDS: Sodium dodecyl sulfate; EDTA: Ethylenediaminetetraacetic acid; PVDF: Polyvinylidene fluoride; HRP: Horseradish peroxidase; ${ }^{3} \mathrm{H}-\mathrm{TdR}$ : ${ }^{3} \mathrm{H}$-thymidine; SD: standard deviation.

\section{Declarations}

\section{Acknowledgements}

Not applicable.

\section{Funding}

This work was supported by the Basic Scientific Research Operating Expense Project of Heilongjiang Provincial Department of Education; Contract grant number: No. 2019-KYYWF-0982.

\section{Authors' Contributions}

SPL made substantial contributions to the conception and design of the study. HZW drafted the manuscript and revised it critically for important intellectual content. ZM, FSG, WJ and YL have agreed to be accountable for all aspects of the work in ensuring that questions related to the accuracy or integrity of any part of the work are appropriately investigated and resolved. All authors read and approved the final manuscript.

\section{Competing interests}

The authors declare that they have no competing interests.

\section{Consent for publication}

Not applicable. 


\section{Ethics approval and consent to participate}

Not applicable.

\section{References}

1. Arbyn $M$, Weiderpass $E$, Bruni L, et al. Estimates of incidence and mortality of cervical cancer in 2018 : a worldwide analysis. Lancet Glob Health. 2020; 8(2): e191-e03.

2. Di J, Rutherford S, Chu C. Review of the CervicalCancerBurden and PopulationBased Cervical Cancer Screening in China. Asian Pac J Cancer Prev. 2015; 16(17): 7401-7.

3. Fang J, Zhang H, Jin S. Epigenetics and cervicalcancer: from pathogenesis to therapy.Tumour Biol. 2014; 35(6): 5083-93.

4. Takekuma $\mathrm{M}$, Kasamatsu $\mathrm{Y}$, Kado N, et al. The issues regarding postoperative adjuvant therapy and prognostic risk factors for patients with stage I-II cervicalcancer: A review. J Obstet Gynaecol Res. 2017; 43(4): 617-26.

5. Tewari AK, Stockert JA, Yadav SS, et al. Inflammationand ProstateCancer. Adv Exp Med Biol. 2018; 1095: 41-65.

6. Sadri Nahand J, Moghoofei M, Salmaninejad A, et al: Pathogenic role of exosomes and microRNAs in HPV-mediated inflammationand cervicalcancer: A review. Int J Cancer. 2020; 146(2): 305-20.

7. Xie X, Yang M, Ding Y, et al. Microbial infection, inflammationand epithelial ovariancancer. Oncol Lett. 2017; 14(2): 1911-9.

8. Katoh M. Multi-layered prevention and treatment of chronicinflammation, organ fibrosis and cancerassociated with canonical WNT/ß-catenin signaling activation (Review). Int J Mol Med. 2018; 42(2): 713-25.

9. Monkkonen T, Debnath J. Inflammatorysignaling cascades and autophagy in cancer. 2018; 14(2): 190-8.

10. Liu X, Zhao W, Wang W, et al. Puerarin suppresses LPS-induced breast cancercell migration, invasion and adhesion by blockage NF-kB and Erk pathway. Biomed Pharmacother. 2017; 92: 429-36.

11. Kim CG, Lee H, Gupta N, et al. Role of Forkhead Box Class 0 proteins in cancerprogression and metastasis. Semin Cancer Biol. 2018; 50: 142-51.

12. He A, Shao J, Zhang Y, et al. CD200Fc reduces LPS-induced IL-1 $\beta$ activation in human cervicalcancer cells by modulating TLR4-NF-KB and NLRP3 inflammasome pathway. 2017; 8(20): 33214-24.

13. Zhang B, Gui LS, Zhao XL, et al. FOXO1 is a tumor suppressor in cervical cancer. Genet Mol Res. 2015; 14(2): 6605-16.

14. Goto T, Takano M. Transcriptionalrole of FOXO1 in drug resistance through antioxidant defense systems. Adv Exp Med Biol. 2009; 665: 171-9. 
15. Liu LM, Liang DY, Ye CG, et al. The UII/UT system mediates upregulation of proinflammatory cytokinesthrough p38 MAPK and NF-KB pathways in LPS-stimulated Kupffer cells. PLoS One. 2015; 10(3): e0121383.

16. Shen JQ, Zhang ZX, Shen CF, et al. Anticarcinogenic effect of Umbelliferone in human prostatecarcinoma: An in vitro study. J BUON. 2017; 22(1): 94-101.

17. Veena VK, Popavath RN, Kennedy K, et al. In vitro antiproliferative, pro-apoptotic, antimetastatic and anti-inflammatory potential of 2,4-diacetylphloroglucinol (DAPG) by Pseudomonas aeruginosa strain FP10. 2015; 20(10): 1281-95.

18. Yang H, Fang Z, Qu X, et al. Procyanidin Compound (PC) Suppresses LipopolysaccharideInduced CervicalCancer Cell Proliferation Through Blocking the TLR4/NF-kB Pathway. Cancer Manag Res. 2020; 12: 497-509.

19. Yang JB, Zhao ZB, Liu QZ, et al. FoxO1is a regulator of MHC-Il expression and anti-tumor effect of tumor-associated macrophages. 2018; 37(9): 1192-204.

20. Essers MA, de Vries-Smits LM, Barker N, et al. Functional interaction between beta-catenin and FOXO in oxidativestress Science. 2005; 308(5725): 1181-1184.

21. Akasaki Y, Alvarez-Garcia O, Saito M, et al. FoxO transcription factors support oxidativestress resistance in human chondrocytes. Arthritis Rheumatol. 2014; 66(12): 334958.

22. Tang T, Wong HK, Gu W, et al. MicroRNA-182 plays an onco-miRNA role in cervical cancer. Gynecol Oncol. 2013; 129(1): 199-208.

23. Yan Y, Huang H. Interplay Among PI3K/AKT, PTEN/FOXO and AR Signaling in Prostate Adv Exp Med Biol. 2019; 1210: 319-31.

24. Li W, Yi J, Zheng X, et al. miR-29c plays a suppressive role in breastcancer by targeting the TIMP3/STAT1/FOXO1 Clin Epigenetics. 2018; 10: 64.

25. Zhang N, Qiu J, Zheng T, et al. Goserelin promotes the apoptosis of epithelialovarian cancer cells by upregulating forkhead box 01 through the PI3K/AKT signaling pathway. Oncol Rep. 2018; 39(3): 1034-42.

26. Yan $\mathrm{H}$, Wu A. FOXO1is crucial in glioblastoma cell tumorigenesis and regulates the expression of SIRT1 to suppress senescence in the brain. Mol Med Rep. 2018; 17(2): 2535-42.

27. Prasad SB, Yadav SS, Das M, et al. Down Regulation of FOXO1Promotes Cell Proliferation in Cervical Cancer. J Cancer. 2014; 5(8): 655-62.

28. Wang L, Scott I, Zhu L, et al. GCN5L1 modulates cross-talk between mitochondriaand cell signaling to regulate FoxO1 stability and gluconeogenesis. Nat Commun. 2017; 8(1): 523.

29. Li DX, Wang CN, Wang Y, et al. NLRP3 inflammasome-dependent pyroptosisand apoptosis in hippocampus neurons mediates depressive-like behavior in diabetic mice. Behav Brain Res. 2020; 391: 112684. 
30. Shi C, Wang Q, Rao Z, et al. Diabetes induces hepatocyte pyroptosisby promoting oxidative stressmediated NLRP3 inflammasome activation during liver ischaemia and reperfusion injury. Ann Transl Med. 2020; 8(12): 739.

31. Liu X, Cui Y, Li M, et al. Cobalt protoporphyrin induces HO-1expression mediated partially by FOXO1 and reduces mitochondria-derived reactive oxygen species production. PLoS One. 2013; 8(11): e80521.

\section{Figures}


a:

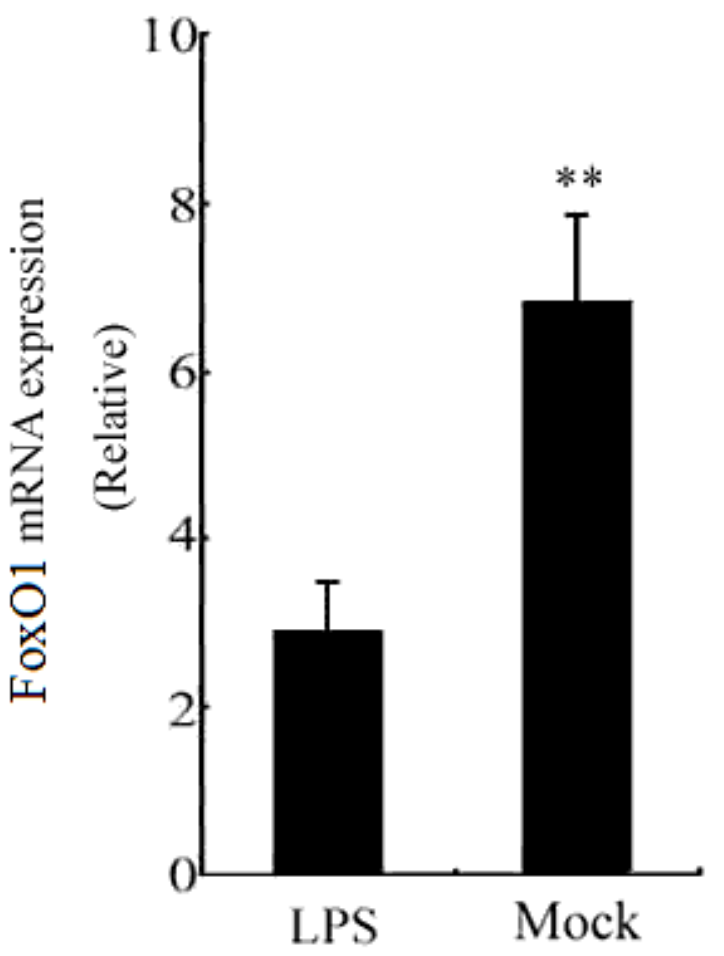

c:

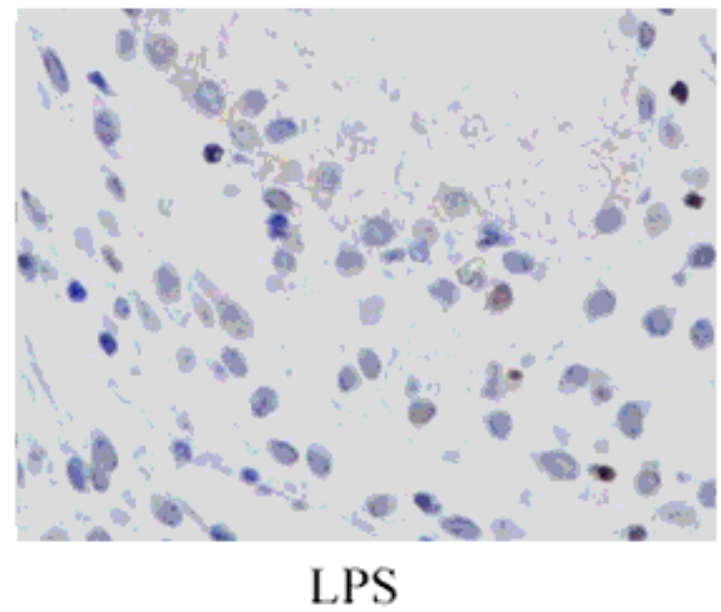

b:
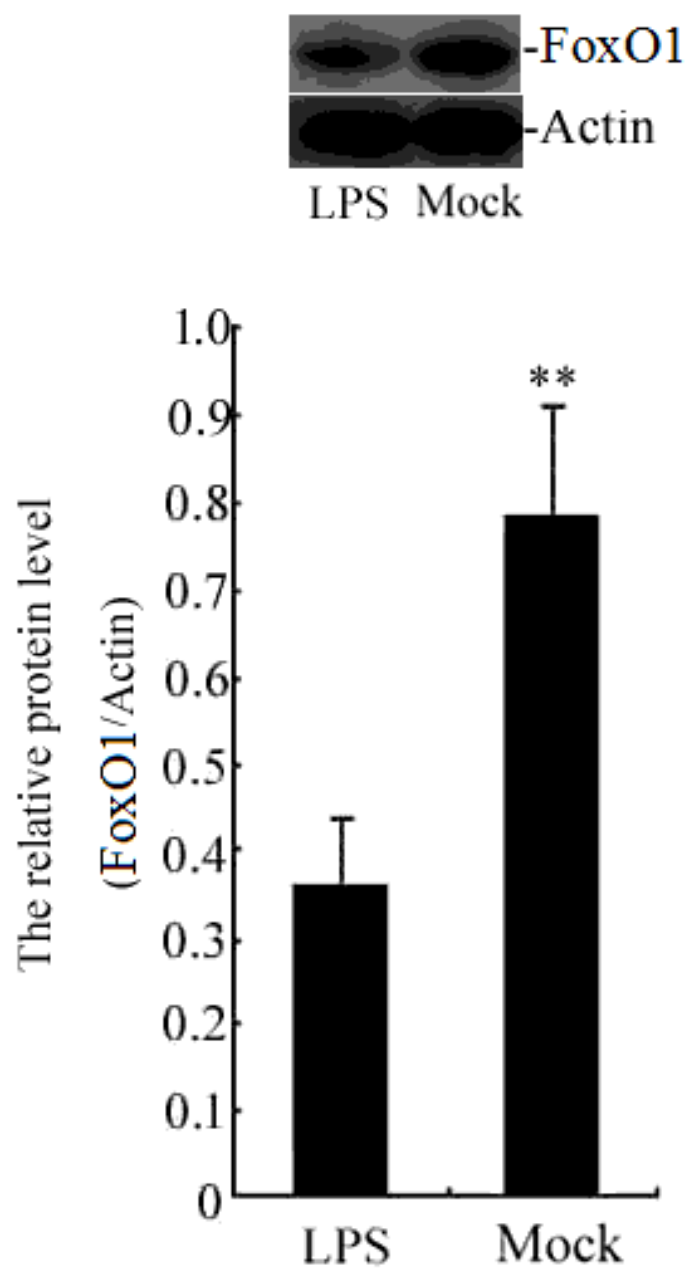

\section{Figure 1}

Effects of LPS on FoxO1 expression in SiHa cells. SiHa cells were stimulated with $40 \mu \mathrm{g} / \mathrm{ml}$ LPS for $24 \mathrm{~h}$. (a) The mRNA level of FoxO1 was examined by qRT-PCR analysis. (b) The protein levels of FoxO1 in lysates of $\mathrm{SiHa}$ cells were measured by western blot assay. The bar chart showed the ratio of FoxO1 to $\beta$ actin at each groups. (c) The expression level and localization of Fox01 protein was detected using 
immunohistochemical staining analysis. SiHa cells with brown cytoplasm were positive (Red arrows). Data are the mean \pm S.D. of three independent experiments. ${ }^{* \star} p<0.01$ versus mock group.

a:

b:
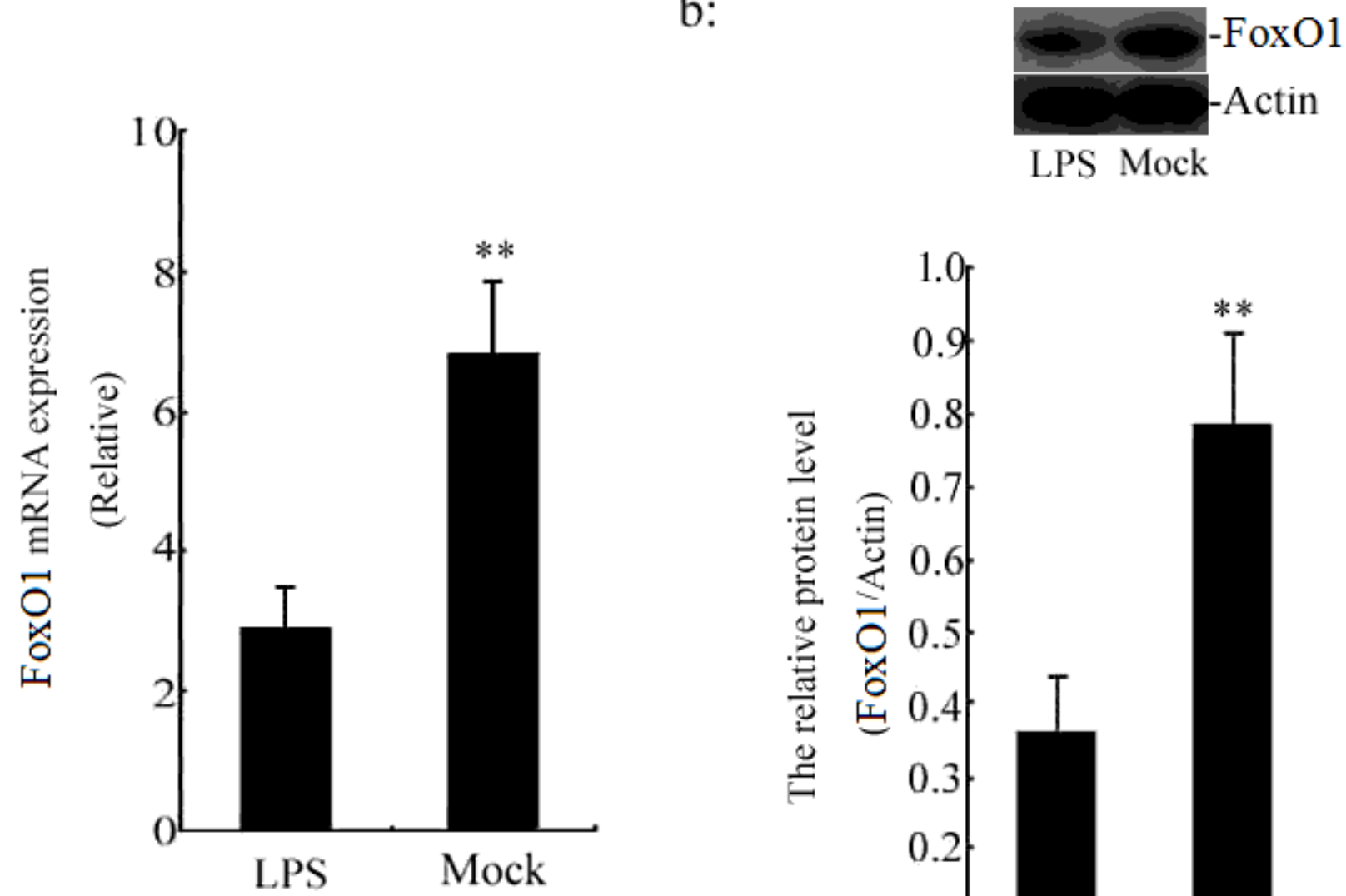

c:
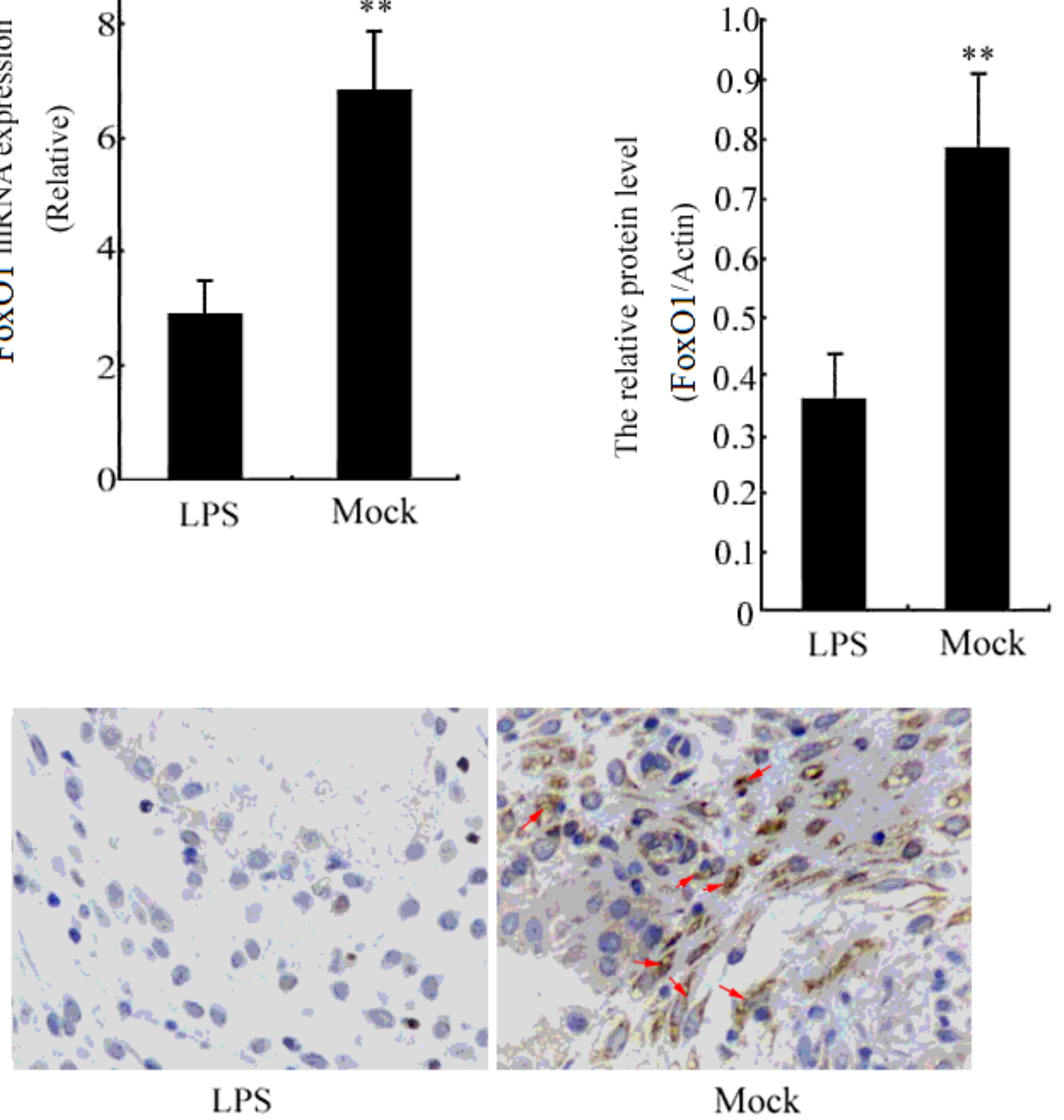

Figure 1

Effects of LPS on FoxO1 expression in SiHa cells. SiHa cells were stimulated with $40 \mu \mathrm{g} / \mathrm{ml} \mathrm{LPS}$ for $24 \mathrm{~h}$. (a) The mRNA level of Fox01 was examined by qRT-PCR analysis. (b) The protein levels of Fox01 in lysates of SiHa cells were measured by western blot assay. The bar chart showed the ratio of FoxO1 to $\beta$ - 
actin at each groups. (c) The expression level and localization of Fox01 protein was detected using immunohistochemical staining analysis. SiHa cells with brown cytoplasm were positive (Red arrows). Data are the mean \pm S.D. of three independent experiments. ${ }^{* \star} p<0.01$ versus mock group.

a: b:
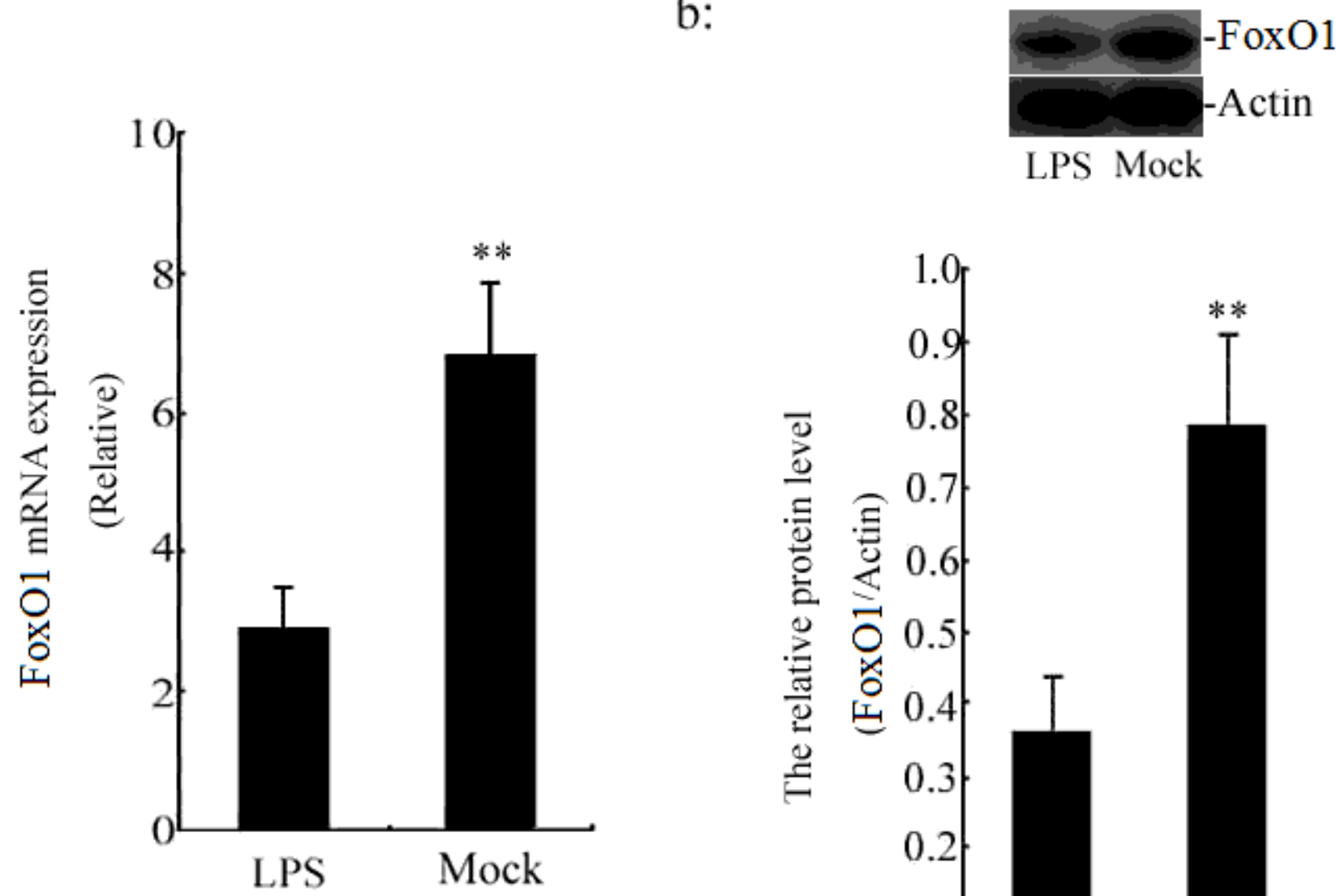

c:
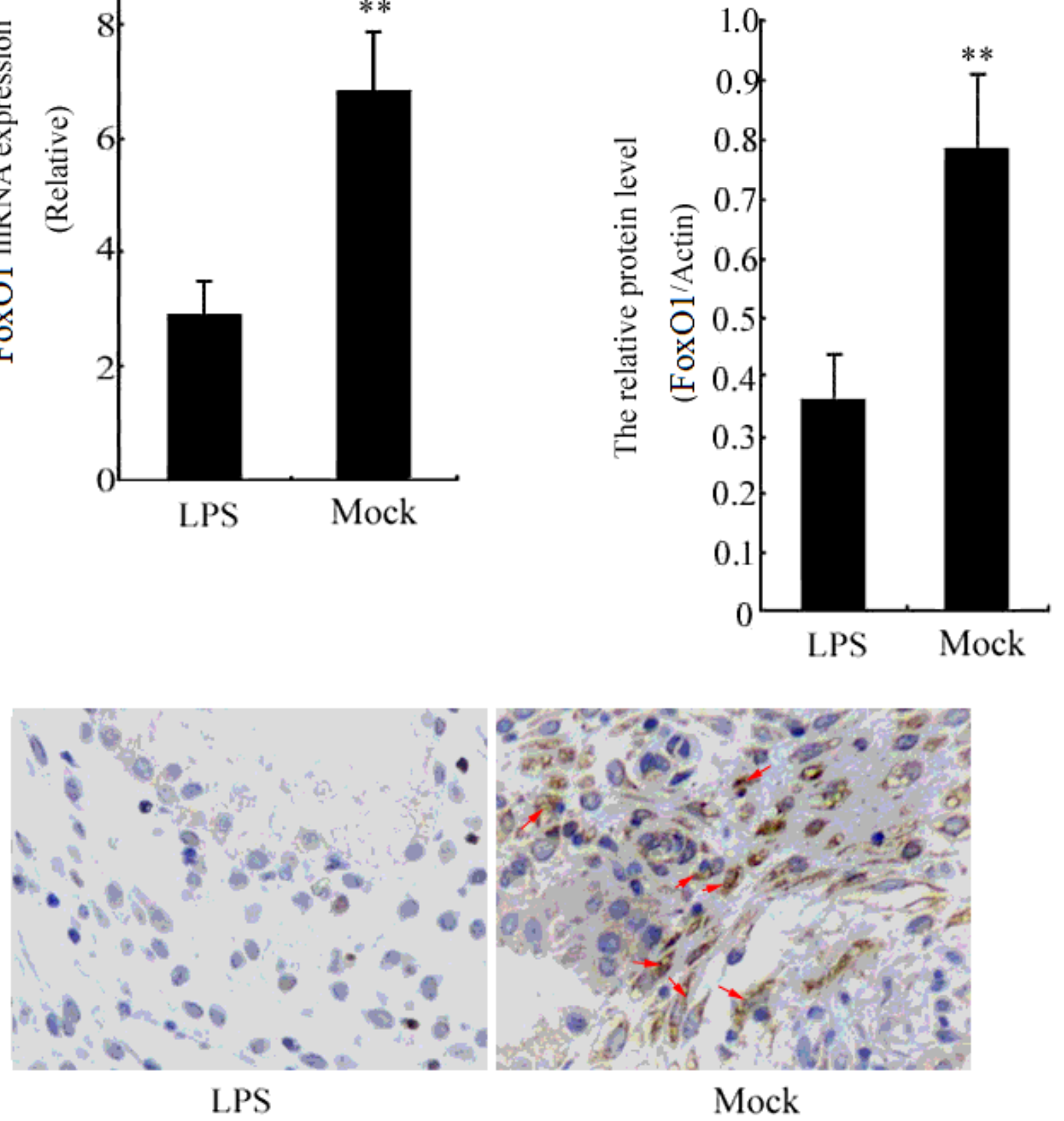

Figure 1

Effects of LPS on Fox01 expression in SiHa cells. SiHa cells were stimulated with $40 \mu \mathrm{g} / \mathrm{ml}$ LPS for $24 \mathrm{~h}$. (a) The mRNA level of Fox01 was examined by qRT-PCR analysis. (b) The protein levels of FoxO1 in 
lysates of SiHa cells were measured by western blot assay. The bar chart showed the ratio of FoxO1 to $\beta$ actin at each groups. (c) The expression level and localization of Fox01 protein was detected using immunohistochemical staining analysis. SiHa cells with brown cytoplasm were positive (Red arrows). Data are the mean \pm S.D. of three independent experiments. ${ }^{* *} p<0.01$ versus mock group.

a:

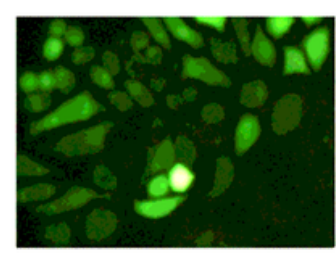

FoxOl siRNA

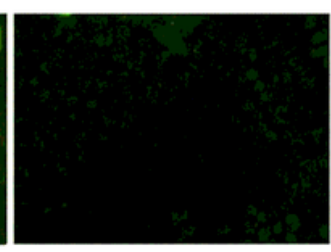

negative siRNA

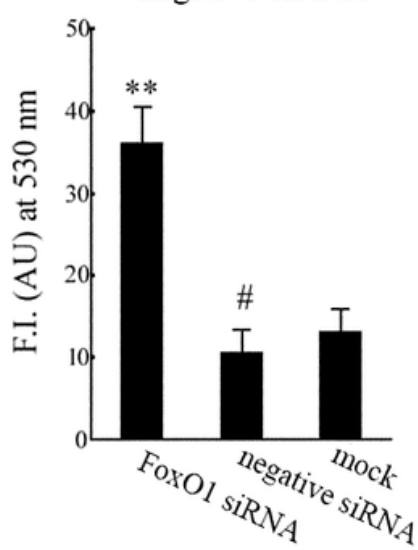

b:

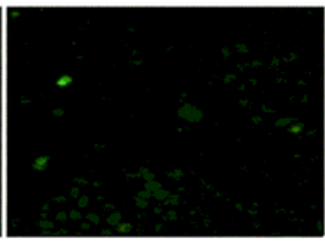

mock

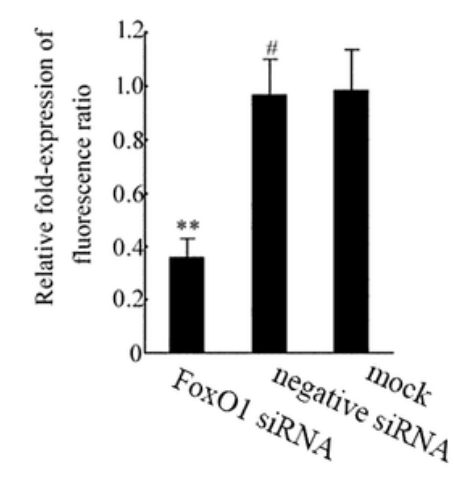

c:

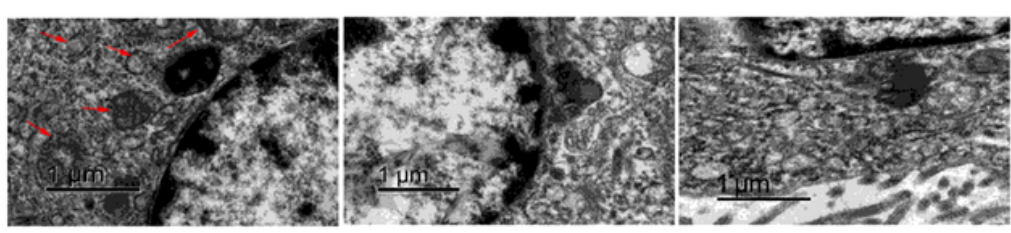

FoxOl siRNA

negative siRNA

mock

\section{Figure 2}

Effect of silencing of FoxO1 gene on mitochondrial function of SiHa cells. The SiHa cells were transfected with Fox01 siRNA or negative siRNA for $48 \mathrm{~h}$. (a) Intracellular ROS production was detected by H2DCFDA fluorescence (Green). The data are means \pm S.D. of three separate experiments. ${ }^{\star *} \mathrm{p}<0.01$, $\# p>0.05$ versus mock group. (b) The change of mitochondrial membrane potential was analyzed by staining with fluorescence of JC-1 (590: $527 \mathrm{~nm}$ fluorescence ratio). The data are presented as mean \pm S.D. $(n=3) .{ }^{\star \star} p<0.01, \# p>0.05$ versus mock group. (c) Representative images of mitochondrial morphology visualized by transmission electron microscopy. Mitochondrial swelling and vesicular formation were observed (Red arrows). Scale bar: $1 \mu \mathrm{m}$. 
a:

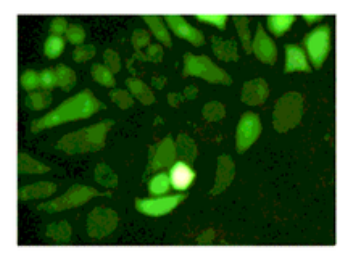

FoxOl siRNA

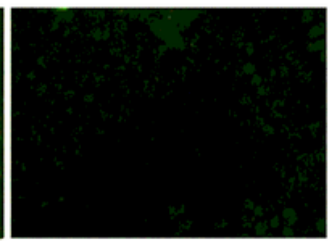

negative siRNA

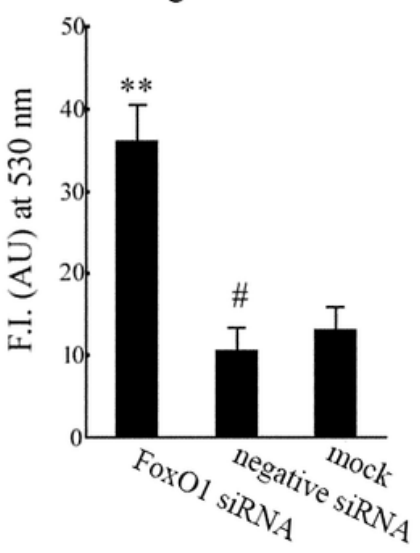

b:

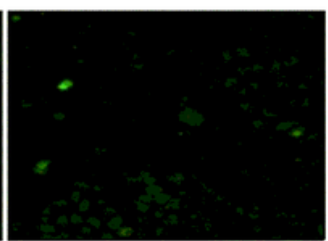

mock

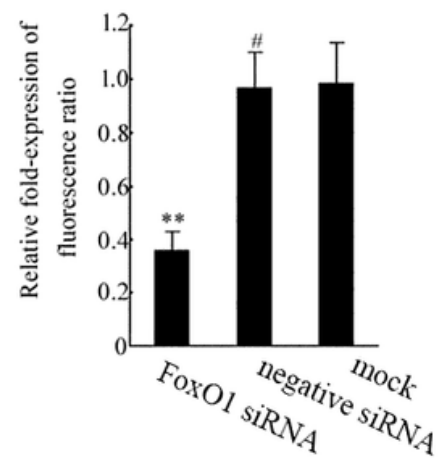

c:

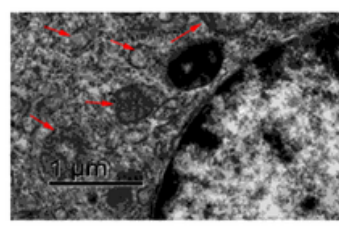

FoxO1 siRNA

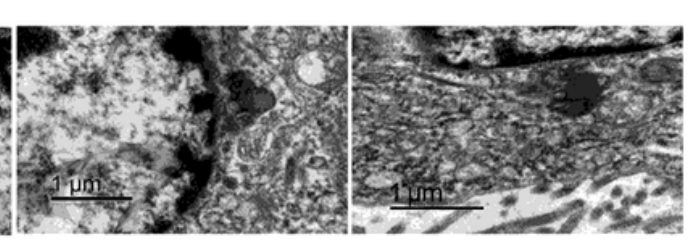

negative siRNA

mock

\section{Figure 2}

Effect of silencing of FoxO1 gene on mitochondrial function of SiHa cells. The SiHa cells were transfected with Fox01 siRNA or negative siRNA for $48 \mathrm{~h}$. (a) Intracellular ROS production was detected by H2DCFDA fluorescence (Green). The data are means \pm S.D. of three separate experiments. ${ }^{* \star} p<0.01$, $\# p>0.05$ versus mock group. (b) The change of mitochondrial membrane potential was analyzed by staining with fluorescence of JC-1 (590: $527 \mathrm{~nm}$ fluorescence ratio). The data are presented as mean \pm S.D. $(n=3) .{ }^{\star} p<0.01, \# p>0.05$ versus mock group. (c) Representative images of mitochondrial morphology visualized by transmission electron microscopy. Mitochondrial swelling and vesicular formation were observed (Red arrows). Scale bar: $1 \mu \mathrm{m}$. 
a:

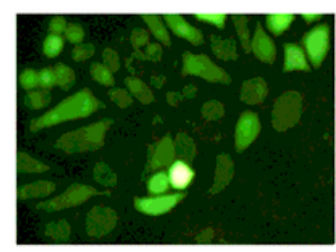

FoxOl siRNA

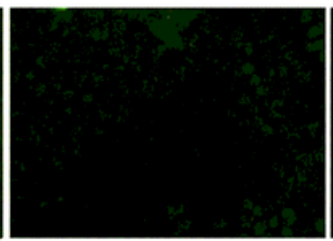

negative siRNA

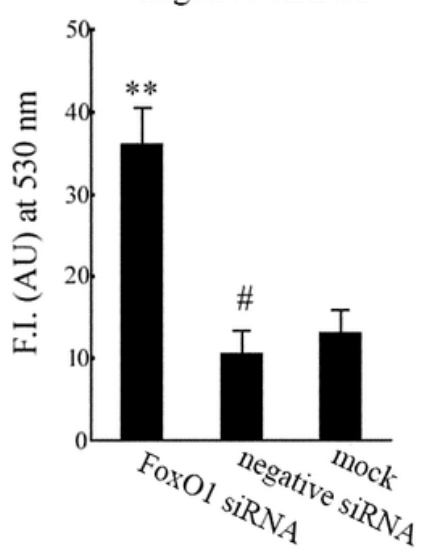

b:

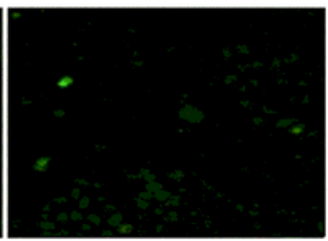

mock

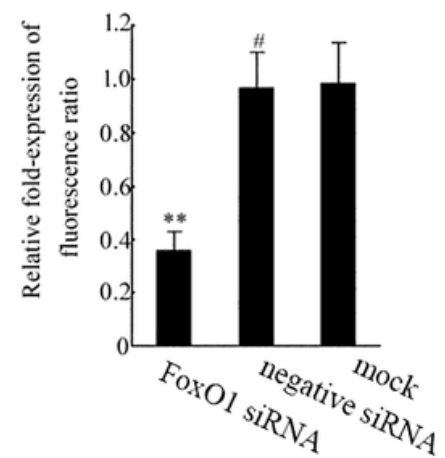

c:

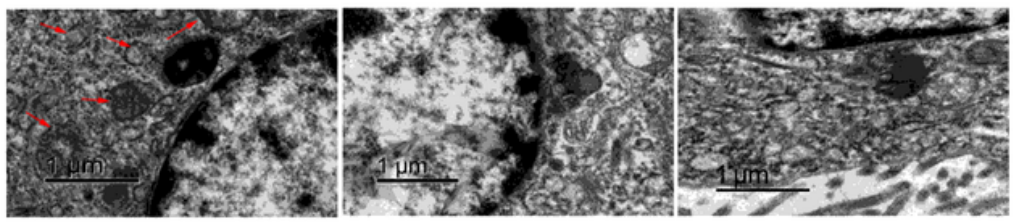

FoxOl siRNA negative siRNA

\section{Figure 2}

Effect of silencing of FoxO1 gene on mitochondrial function of SiHa cells. The SiHa cells were transfected with Fox01 siRNA or negative siRNA for $48 \mathrm{~h}$. (a) Intracellular ROS production was detected by H2DCFDA fluorescence (Green). The data are means \pm S.D. of three separate experiments. ${ }^{* \star} p<0.01$, $\# p>0.05$ versus mock group. (b) The change of mitochondrial membrane potential was analyzed by staining with fluorescence of JC-1 (590: $527 \mathrm{~nm}$ fluorescence ratio). The data are presented as mean \pm S.D. $(n=3) .{ }^{\star} p<0.01, \# p>0.05$ versus mock group. (c) Representative images of mitochondrial morphology visualized by transmission electron microscopy. Mitochondrial swelling and vesicular formation were observed (Red arrows). Scale bar: $1 \mu \mathrm{m}$.

a:

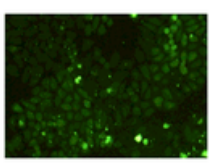

LPS

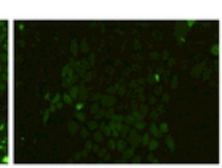

LPS + FoxOl vector

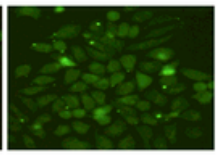

LPS+ empty vector

LPS+ metformin

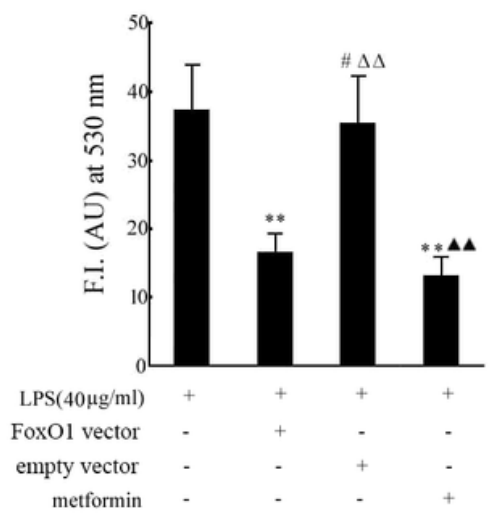

c:

b:

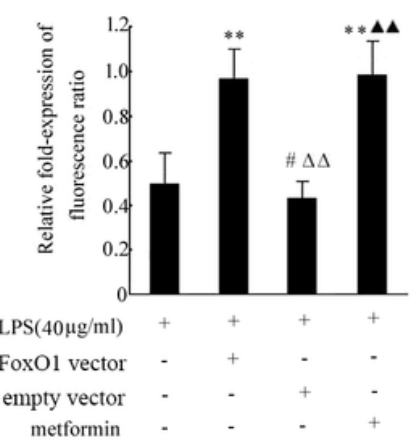

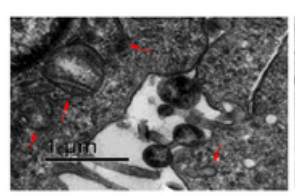

LPS

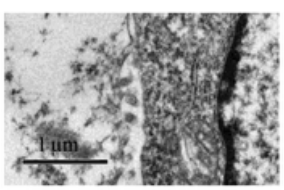

LPS+ FoxOl vector

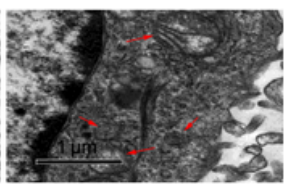

LPS+ empty vector

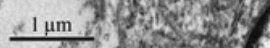

LPS+ metformin 


\section{Figure 3}

Effect of overexpression of FoxO1 on mitochondrial function in LPS-stimulated SiHa cells. The SiHa cells were stimulated with $40 \mu \mathrm{g} / \mathrm{ml}$ LPS for $24 \mathrm{~h}$ under transfection with pcDNA3.1-Fox01 vector $(2 \mu \mathrm{g} / \mathrm{ml})$ or pcDNA3.1-empty vector $(2 \mu \mathrm{g} / \mathrm{ml})$ for $48 \mathrm{~h}$ respectively. (a) Intracellular ROS levels were measured by H2DCFDA fluorescence (Green). Data represent the means \pm S.D. of three independent experiments $(n=$ 3). ${ }^{* \star} p<0.01, \# p>0.05$ versus LPS alone-treated group; $\Delta \Delta p<0.01$ versus LPS $(+)$ and Fox01 vector $(+)$ group; $\Delta \Delta \mathrm{p}<0.01$ versus LPS $(+)$ and empty vector $(+)$ group. (b) Mitochondrial membrane potential was detected by the change of $\mathrm{JC}-1$ fluorescence. ${ }^{*} \mathrm{p}<0.01$, \#p $>0.05$ versus LPS alone-treated group; $\Delta \Delta \mathrm{p}<0.01$ versus LPS (+) and Fox01 vector (+) group; $\mathbf{\Delta} \Delta \mathrm{p}<0.01$ versus LPS (+) and empty vector (+) group. (c) Representative transmission electron microscopy images. Mitochondria became smaller, punctate, and the length was significantly shortened (Red arrows). Scale bar: $1 \mu \mathrm{m}$.

a:

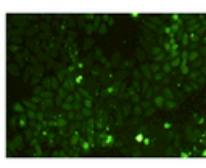

LPS

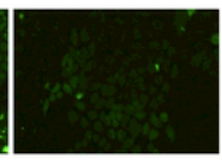

LPS + FoxOl vector

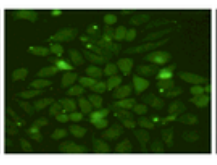

LPS+ empty vector

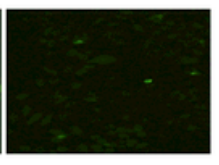

LPS+ metformin

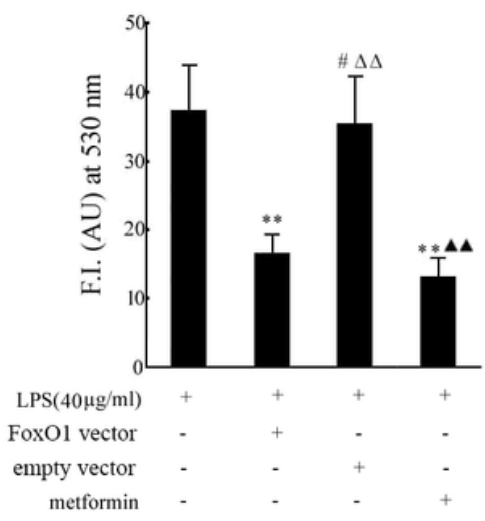

c:

b:

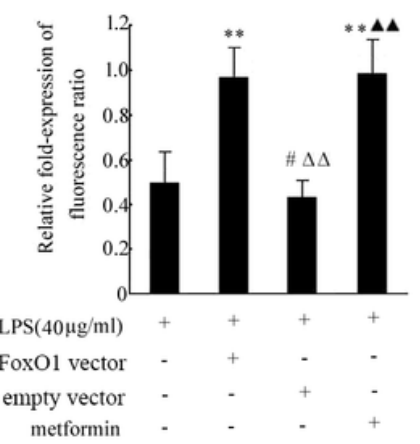

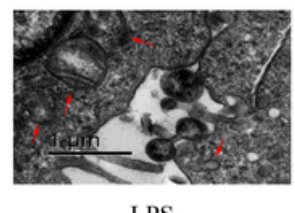

LPS

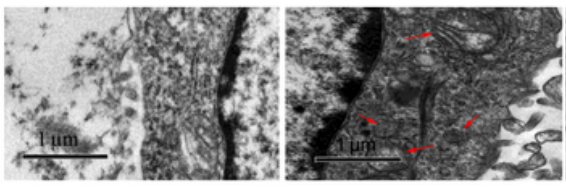

LPS+ empty vector

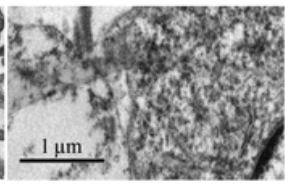

LPS+ metformin

\section{Figure 3}

Effect of overexpression of FoxO1 on mitochondrial function in LPS-stimulated $\mathrm{SiHa}$ cells. The SiHa cells were stimulated with $40 \mu \mathrm{g} / \mathrm{ml}$ LPS for $24 \mathrm{~h}$ under transfection with pcDNA3.1-Fox01 vector $(2 \mu \mathrm{g} / \mathrm{ml})$ or pcDNA3.1-empty vector $(2 \mu \mathrm{g} / \mathrm{ml})$ for $48 \mathrm{~h}$ respectively. (a) Intracellular ROS levels were measured by H2DCFDA fluorescence (Green). Data represent the means \pm S.D. of three independent experiments $(\mathrm{n}=$ 3). ${ }^{\star \star} \mathrm{p}<0.01, \# p>0.05$ versus LPS alone-treated group; $\Delta \Delta \mathrm{p}<0.01$ versus LPS $(+)$ and Fox01 vector $(+)$ group; $\boldsymbol{\Delta} \Delta \mathrm{p}<0.01$ versus LPS (+) and empty vector (+) group. (b) Mitochondrial membrane potential was detected by the change of JC-1 fluorescence. ${ }^{*} \mathrm{p}<0.01$, \#p $>0.05$ versus LPS alone-treated group; $\Delta \Delta p<0.01$ versus LPS (+) and Fox01 vector (+) group; $\Delta \mathbf{\Delta p}<0.01$ versus LPS (+) and empty vector (+) group. (c) Representative transmission electron microscopy images. Mitochondria became smaller, punctate, and the length was significantly shortened (Red arrows). Scale bar: $1 \mu \mathrm{m}$. 
a:

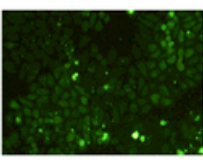

LPS

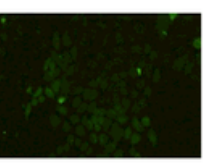

LPS + FoxOl vector

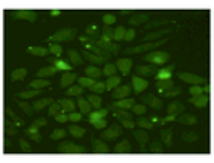

LPS+ empty vector

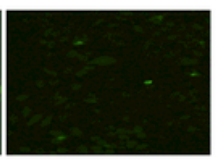

LPS+ metformin

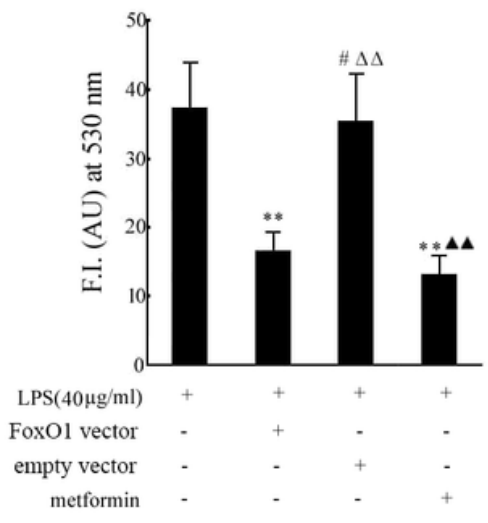

c:

b:

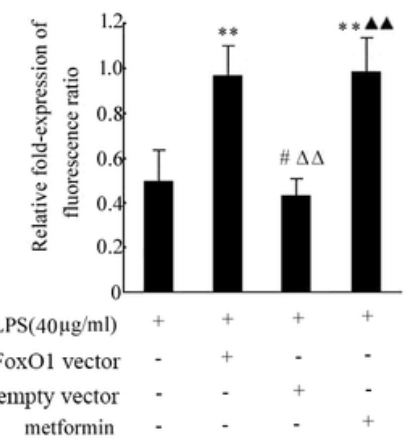

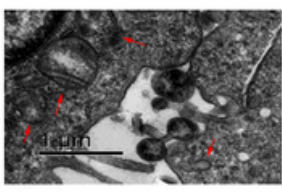

LPS

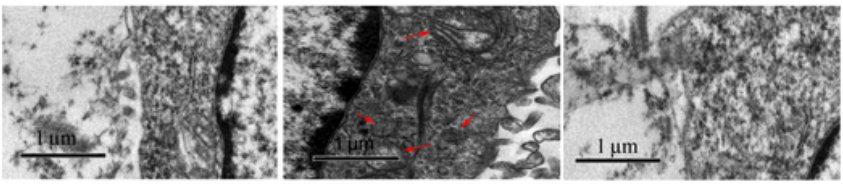

LPS+ empty vector

LPS+ metformin

\section{Figure 3}

Effect of overexpression of FoxO1 on mitochondrial function in LPS-stimulated SiHa cells. The SiHa cells were stimulated with $40 \mu \mathrm{g} / \mathrm{ml}$ LPS for $24 \mathrm{~h}$ under transfection with pcDNA3.1-Fox01 vector $(2 \mu \mathrm{g} / \mathrm{ml})$ or pcDNA3.1-empty vector $(2 \mu \mathrm{g} / \mathrm{ml})$ for $48 \mathrm{~h}$ respectively. (a) Intracellular ROS levels were measured by H2DCFDA fluorescence (Green). Data represent the means \pm S.D. of three independent experiments $(n=$ 3). ${ }^{* \star} \mathrm{p}<0.01, \# \mathrm{p}>0.05$ versus LPS alone-treated group; $\Delta \Delta \mathrm{p}<0.01$ versus LPS $(+)$ and Fox01 vector (+) group; $\boldsymbol{\Delta} \Delta \mathrm{p}<0.01$ versus LPS (+) and empty vector (+) group. (b) Mitochondrial membrane potential was detected by the change of $\mathrm{JC}-1$ fluorescence. ${ }^{*} \mathrm{p}<0.01$, $\# \mathrm{p}>0.05$ versus LPS alone-treated group; $\Delta \Delta \mathrm{p}<0.01$ versus LPS (+) and Fox01 vector (+) group; $\mathbf{\Delta} \mathbf{\Delta} \mathrm{p}<0.01$ versus LPS (+) and empty vector (+) group. (c) Representative transmission electron microscopy images. Mitochondria became smaller, punctate, and the length was significantly shortened (Red arrows). Scale bar: $1 \mu \mathrm{m}$. 
a:

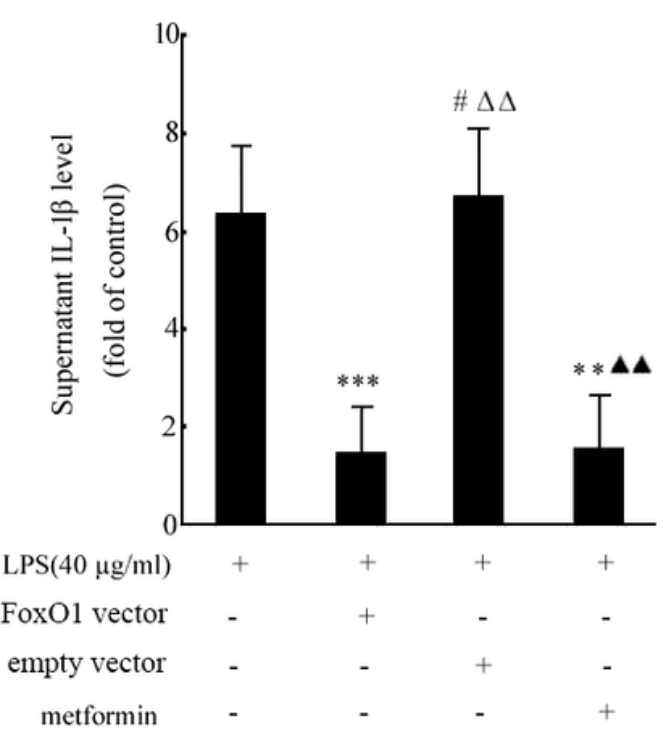

b:
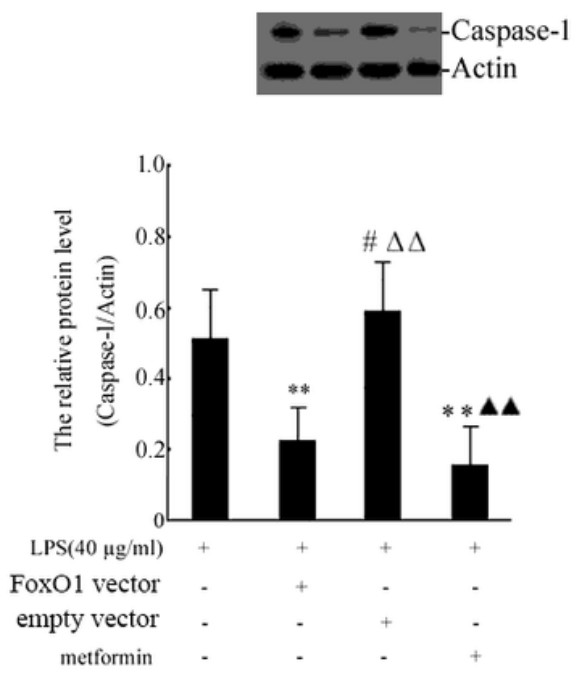

c:
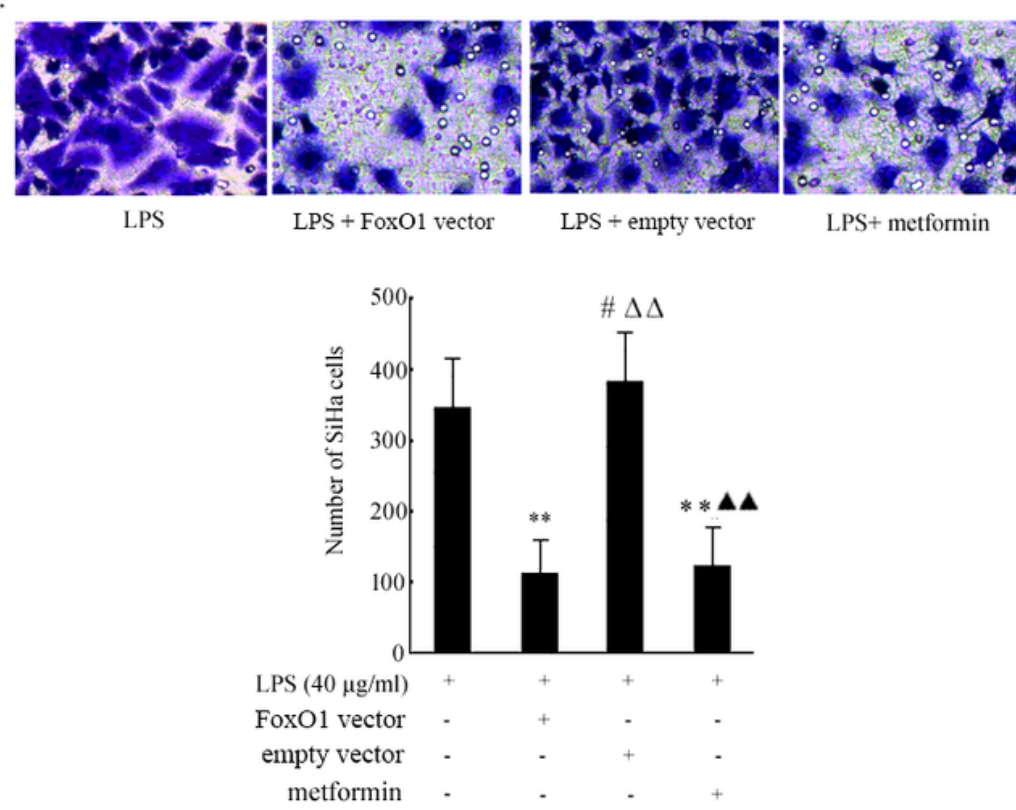

$\mathrm{d}$ :

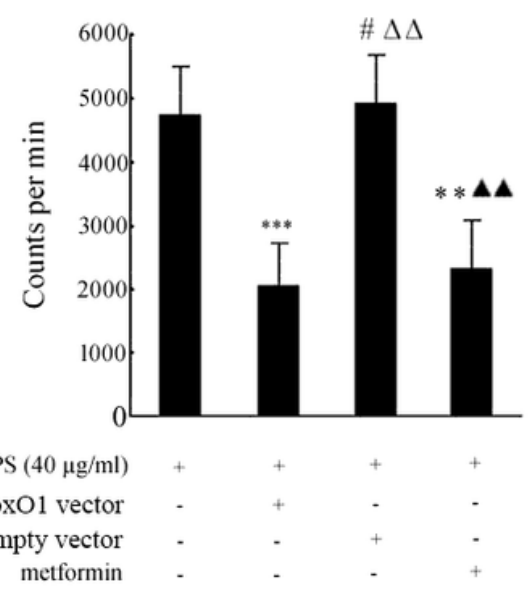

Figure 4

Effect of overexpression of FoxO1 on biological function in LPS-stimulated SiHa cells. The SiHa cells were stimulated with $40 \mu \mathrm{g} / \mathrm{ml}$ LPS for $24 \mathrm{~h}$ under transfection with pcDNA3.1-Fox01 vector $(2 \mu \mathrm{g} / \mathrm{ml})$ or pcDNA3.1-empty vector $(2 \mu \mathrm{g} / \mathrm{ml})$ for $48 \mathrm{~h}$ respectively. (a) The extracellular levels of IL-1 $\beta$ were exanmined by ELISA assay. Data are the mean \pm S.D. of three independent experiments. ${ }^{\star \star *} p<0.001,{ }^{\star *} p$ $<0.01, \# p>0.05$ versus LPS alone-treated group; $\Delta \Delta p<0.01$ versus LPS (+) and Fox01 vector (+) group; $\boldsymbol{\Delta} \mathbf{\Delta} p<0.01$ versus LPS (+) and empty vector (+) group. (b) The protein levels of caspase- 1 in lysates of $\mathrm{SiHa}$ cells were measured by western blot assay. The bar chart showed the ratio of caspase- 1 to $\beta$-actin at each groups $(n=3) .{ }^{\star \star} p<0.01, \# p>0.05$ versus LPS alone-treated group; $\Delta \Delta p<0.01$ versus LPS (+) and Fox01 vector (+) group; $\mathbf{\Delta} \mathbf{\Delta} p<0.01$ versus LPS (+) and empty vector (+) group. (c) The SiHa cells migration were measured by Transwell migration assay $(n=3)$. ${ }^{\star *} p<0.01, \# p>0.05$ versus LPS alonetreated group; $\Delta \Delta \mathrm{p}<0.01$ versus LPS (+) and Fox01 vector (+) group; $\boldsymbol{\Delta} \mathbf{\Delta} p<0.01$ versus LPS (+) and empty vector (+) group. (d) $3 \mathrm{H} \mathrm{TdR}$ incorporation was executed to assess the proliferation of SiHa cells. 
The absolute value of CPM showed the proliferation of SiHa cells ( $\mathrm{cpm} / 106 \mathrm{cells})$. Data represent the means \pm S.D. of three independent experiments, ${ }^{\star \star *} p<0.001,{ }^{\star *} p<0.01, \# p>0.05$ versus LPS alonetreated group; $\Delta \Delta p<0.01$ versus LPS (+) and Fox01 vector (+) group; $\mathbf{\Delta} \mathbf{\Delta p}<0.01$ versus LPS (+) and empty vector $(+)$ group.

a:

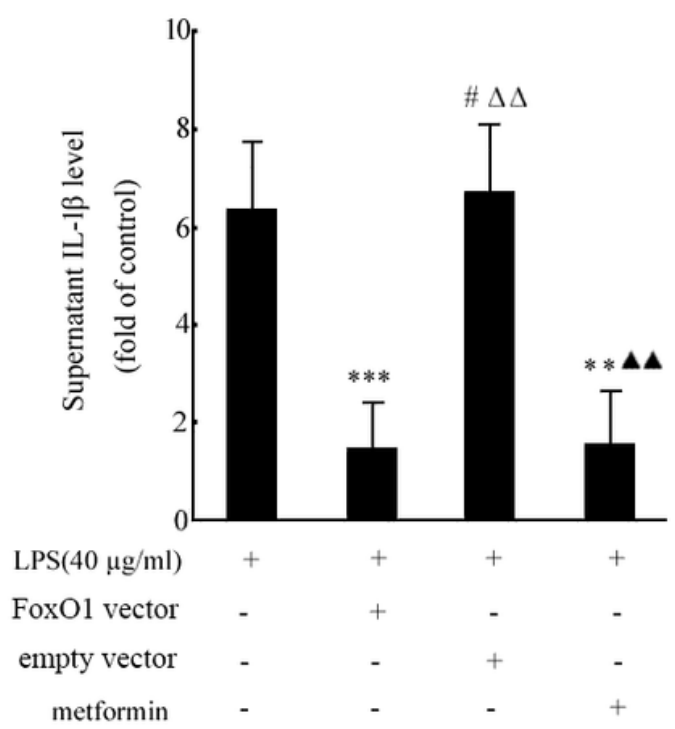

b:

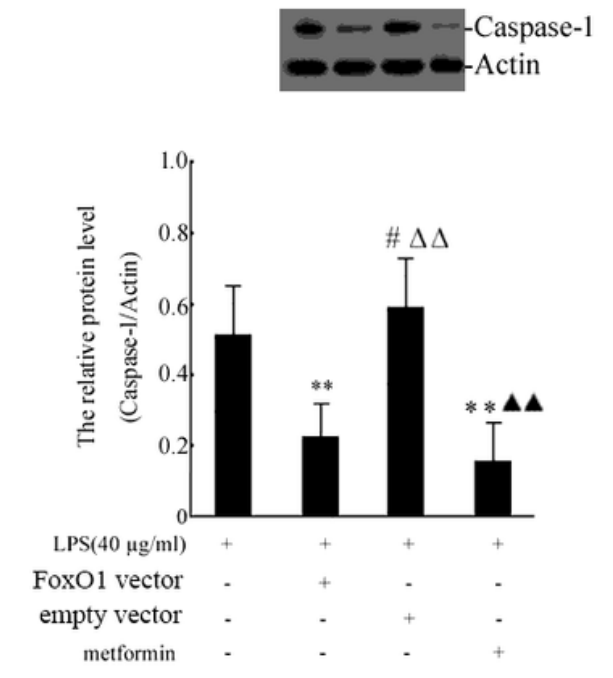

c:
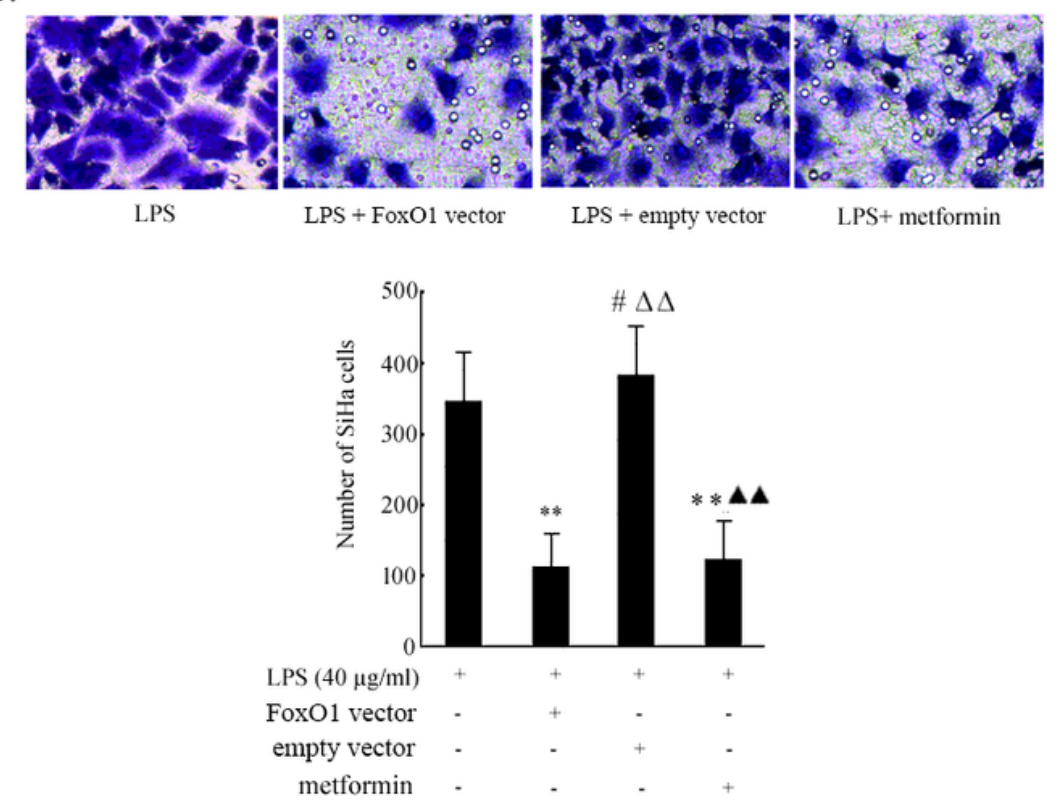

$\mathrm{d}$ :

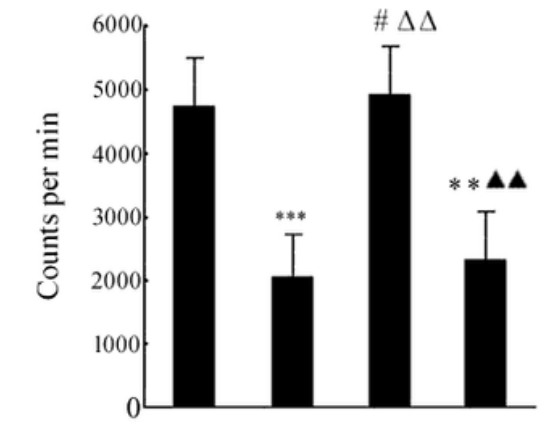

LPS $(40 \mu \mathrm{g} / \mathrm{ml})$ FoxO1 vector empty vector metformin

\section{Figure 4}

Effect of overexpression of FoxO1 on biological function in LPS-stimulated SiHa cells. The SiHa cells were stimulated with $40 \mu \mathrm{g} / \mathrm{ml}$ LPS for $24 \mathrm{~h}$ under transfection with pcDNA3.1-Fox01 vector $(2 \mu \mathrm{g} / \mathrm{ml})$ or pcDNA3.1-empty vector $(2 \mu \mathrm{g} / \mathrm{ml})$ for $48 \mathrm{~h}$ respectively. (a) The extracellular levels of IL-1 $\beta$ were exanmined by ELISA assay. Data are the mean \pm S.D. of three independent experiments. ${ }^{\star \star \star} p<0.001,{ }^{\star *} p$ $<0.01$, \#p $>0.05$ versus LPS alone-treated group; $\Delta \Delta \mathrm{p}<0.01$ versus LPS (+) and Fox01 vector (+) group; $\Delta \mathbf{\Delta} p<0.01$ versus LPS (+) and empty vector (+) group. (b) The protein levels of caspase- 1 in lysates of $\mathrm{SiHa}$ cells were measured by western blot assay. The bar chart showed the ratio of caspase- 1 to $\beta$-actin at each groups $(n=3)$. ${ }^{*} p<0.01, \# p>0.05$ versus LPS alone-treated group; $\Delta \Delta p<0.01$ versus LPS (+) 
and Fox01 vector (+) group; $\boldsymbol{\Delta} \mathbf{\Delta} p<0.01$ versus LPS (+) and empty vector (+) group. (c) The SiHa cells migration were measured by Transwell migration assay $(n=3)$. ${ }^{\star *} p<0.01, \# p>0.05$ versus LPS alonetreated group; $\Delta \Delta p<0.01$ versus LPS (+) and Fox01 vector (+) group; $\boldsymbol{\Delta} \Delta \mathrm{p}<0.01$ versus LPS (+) and empty vector (+) group. (d) $3 \mathrm{H} \mathrm{TdR}$ incorporation was executed to assess the proliferation of $\mathrm{SiHa}$ cells. The absolute value of CPM showed the proliferation of SiHa cells (cpm/106 cells). Data represent the means \pm S.D. of three independent experiments, ${ }^{\star \star \star} p<0.001,{ }^{\star \star} p<0.01, \# p>0.05$ versus LPS alonetreated group; $\Delta \Delta \mathrm{p}<0.01$ versus LPS (+) and Fox01 vector (+) group; $\mathbf{\Delta} \mathbf{\Delta} p<0.01$ versus LPS $(+)$ and empty vector (+) group.

a:

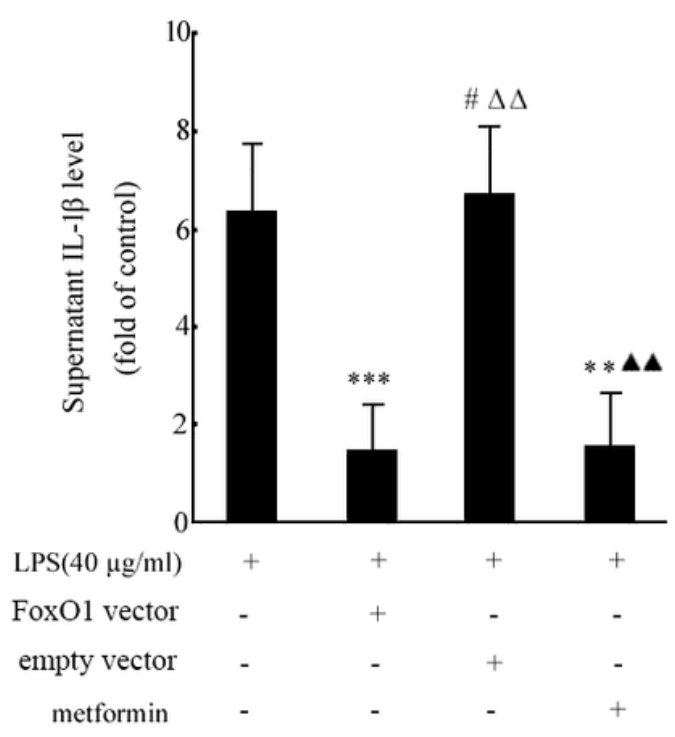

b:
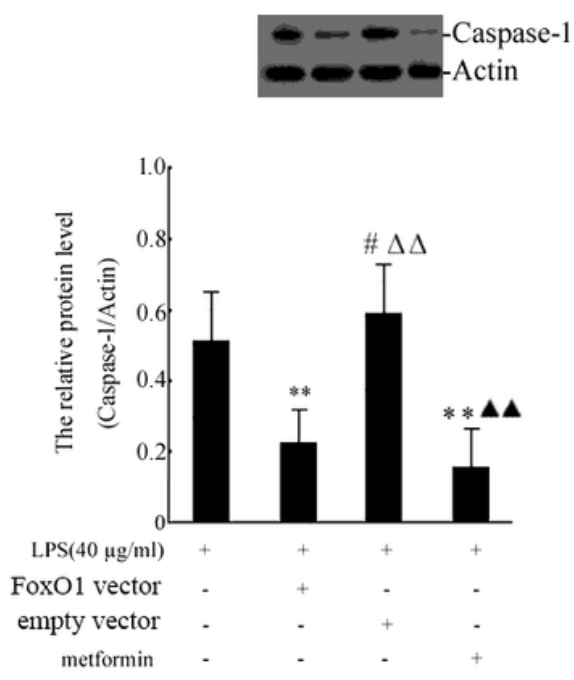

$\mathrm{c}:$
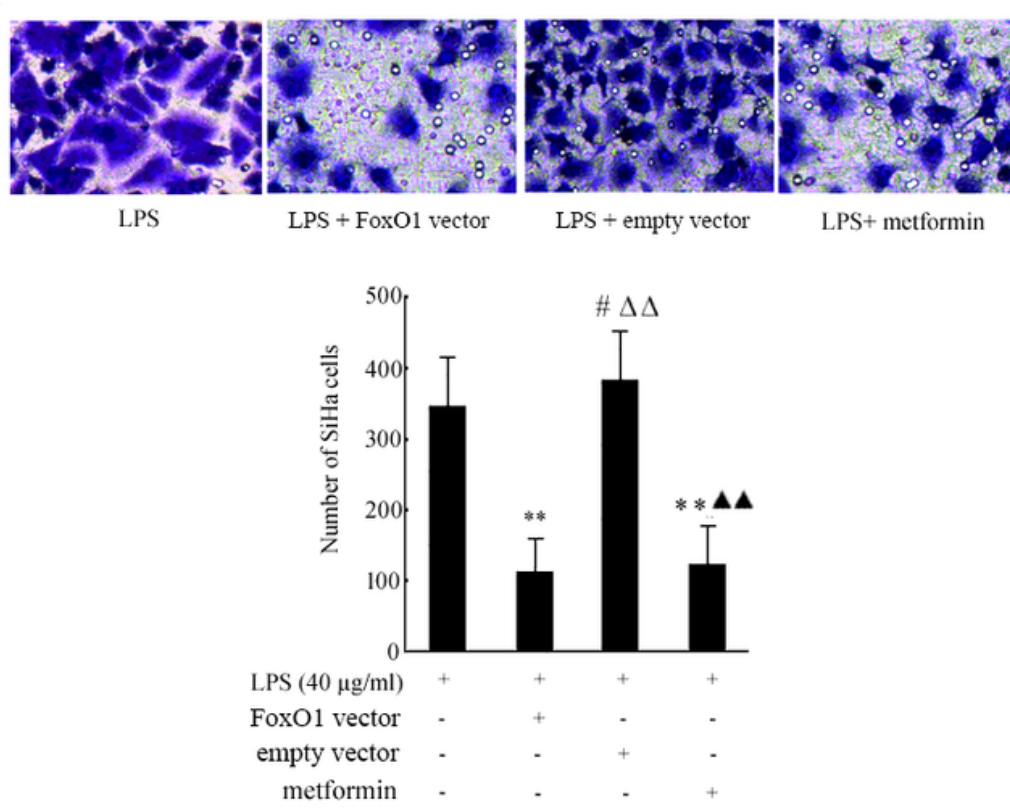

$\mathrm{d}$ :

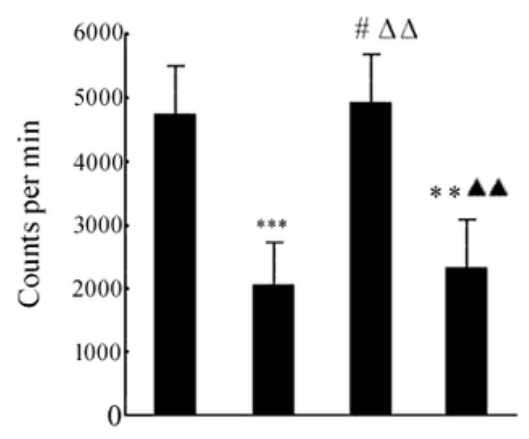

LPS $(40 \mu \mathrm{g} / \mathrm{ml})$

FoxO1 vector

empty vector metformin

\section{Figure 4}

Effect of overexpression of FoxO1 on biological function in LPS-stimulated SiHa cells. The SiHa cells were stimulated with $40 \mu \mathrm{g} / \mathrm{ml}$ LPS for $24 \mathrm{~h}$ under transfection with pcDNA3.1-Fox01 vector $(2 \mu \mathrm{g} / \mathrm{ml})$ or pcDNA3.1-empty vector $(2 \mu \mathrm{g} / \mathrm{ml})$ for $48 \mathrm{~h}$ respectively. (a) The extracellular levels of IL-1 $\beta$ were exanmined by ELISA assay. Data are the mean \pm S.D. of three independent experiments. ${ }^{* \star} p<0.001,{ }^{*} p$ 
$<0.01, \# \mathrm{p}>0.05$ versus LPS alone-treated group; $\Delta \Delta \mathrm{p}<0.01$ versus LPS $(+)$ and Fox01 vector (+) group; $\mathbf{\Delta} \mathbf{\Delta} p<0.01$ versus LPS (+) and empty vector (+) group. (b) The protein levels of caspase- 1 in lysates of $\mathrm{SiHa}$ cells were measured by western blot assay. The bar chart showed the ratio of caspase- 1 to $\beta$-actin at each groups $(n=3) .{ }^{* \star} p<0.01, \# p>0.05$ versus LPS alone-treated group; $\Delta \Delta p<0.01$ versus LPS (+) and Fox01 vector (+) group; $\mathbf{\Delta} \mathbf{\Delta} p<0.01$ versus LPS (+) and empty vector (+) group. (c) The SiHa cells migration were measured by Transwell migration assay $(n=3)$. ${ }^{*} p<0.01, \# p>0.05$ versus LPS alonetreated group; $\Delta \Delta \mathrm{p}<0.01$ versus LPS (+) and Fox01 vector (+) group; $\boldsymbol{\Delta} \mathbf{\Delta} \mathrm{p}<0.01$ versus LPS $(+)$ and empty vector (+) group. (d) $3 \mathrm{H} \mathrm{TdR} \mathrm{incorporation} \mathrm{was} \mathrm{executed} \mathrm{to} \mathrm{assess} \mathrm{the} \mathrm{proliferation} \mathrm{of} \mathrm{SiHa} \mathrm{cells.}$ The absolute value of CPM showed the proliferation of SiHa cells (cpm/106 cells). Data represent the means \pm S.D. of three independent experiments, ${ }^{\star \star \star} \mathrm{p}<0.001,{ }^{\star \star} \mathrm{p}<0.01, \# \mathrm{p}>0.05$ versus LPS alonetreated group; $\Delta \Delta \mathrm{p}<0.01$ versus LPS (+) and Fox01 vector (+) group; $\boldsymbol{\Delta} \mathbf{\Delta} \mathrm{p}<0.01$ versus LPS $(+)$ and empty vector $(+)$ group. 